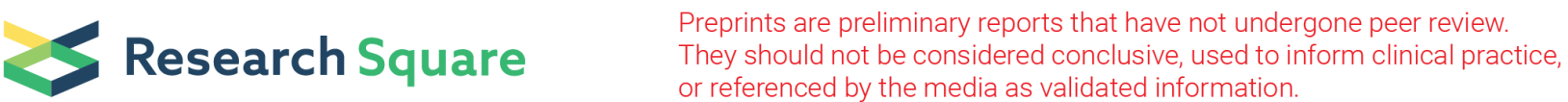 \\ The nerve injuries interfere with the development of psoriasis
}

\section{Bi Qin}

School of Medicine, University of Electronic Science and Technology of China https://orcid.org/00000002-4772-9611

\section{Chaonan Sun}

University of Electronic Science and Technology of China

\section{Ling Chen}

Department of Dermatology, Daping Hospital, Army Medical University

\section{Siyu Wang}

Sichuan Provincial People's Hospital: Sichuan Academy of Medical Sciences and Sichuan People's Hospital

\section{Jianing Yang}

Sichuan Provincial People's Hospital: Sichuan Academy of Medical Sciences and Sichuan People's Hospital

\section{Zhen Xie}

Sichuan Provincial People's Hospital: Sichuan Academy of Medical Sciences and Sichuan People's Hospital

\section{Zhu Shen ( $\nabla$ zhushencq@hotmail.com )}

University of Electronic Science and Technology of China https://orcid.org/0000-0003-2901-4273

\section{Research}

Keywords: The nerve, Psoriasis, Denervation, Psoriasiform, Neuroimmune

Posted Date: October 7th, 2020

DOl: https://doi.org/10.21203/rs.3.rs-85335/v1

License: (c) (1) This work is licensed under a Creative Commons Attribution 4.0 International License. Read Full License 


\section{Abstract}

\section{Background}

The involvement of the nerve in psoriasis development has been suggested by sporadic case or case serial reports.

\section{Objectives}

To provide multiple evidence for the nerve in psoriasis development with a retrospective case review, a literature review and a mouse-based experimental study.

\section{Methods}

Psoriatic patients who had concomitant nerve injuries and such cases from the literatures were reviewed. And, on wild-type mouse level, unilateral denervation surgery was performed on the dorsal skin before and after the induction of psoriasiform dermatitis, respectively. Lesion visual scores were calculated, and lesion biopsies were taken for hematoxylin-eosin (HE) staining, immunofluorescence analysis, and RNA sequencing \& bioinformatics analysis at the time before denervation surgery and the $2^{\text {nd }}, 4^{\text {th }}, 6^{\text {th }}, 8^{\text {th }}$ day after the surgery.

\section{Results}

All clincal cases (20/20) showed that local lesions under the control of injured nerves relieved spontaneously or even cleared/spared, and only about $1 / 3$ experienced partial recurrence. Next, experimental study based on mouse model demonstrated that the unilateral denervation prior to imiquimod application interfered with the enhancement of inflammatory reactions (e.g. adaptive immune response and Th17 cell differentiation pathway) and the induction of ipsilateral psoriasiform dermatitis. On the other hand, the unilateral denervation after the induction of psoriasiform dermatitis promoted the regression of inflammatory reactions (e.g. T cell activation, TNF signaling, and Th17 cell differentiation pathway) and the recovery of ipsilateral dermatitis.

\section{Conclusion}

Our study based on both retrospective clinical case review and wild-type mouse experiments provides multiple evidence for the involvement of the nerve in psoriasis development. Regulation of immune events, including TNF signaling and Th17 cell differentiation, may be one of the mechanisms of the nerve in psoriasis.

\section{Background}

Psoriasis is a common chronic inflammatory skin disease, typically characterized by symmetrically distributed well-defined erythema papules with silvery scales. Its pathological features include excessive 
proliferation of keratinocytes, vasodilation, and inflammatory infiltration. Researches in recent decades demonstrate that immune disorders play an important role in psoriasis development. ${ }^{1}$ And applications of biological antibodies against cytokines with abnormal levels have improved conventional therapeutic effects. ${ }^{2}$ On the other hand, immune cell activation alone might not account for some of the features in psoriasis, e.g. symmetric distribution of lesions, increase of cutaneous nerve fibers, and up-regulation of neuropeptides. More important, clinical phenomena show that some psoriatic patients acquire partial or complete remission in areas where the nerves injured, which directly suggests the crucial roles of the nerve involvement in psoriasis development. ${ }^{3}$

Our study was based on both retrospective clinical case reviews and mouse-based experiments, and provided multiple evidence for the involvement of the nerve in psoriasis development. Regulation of immune events (e.g TNF signaling and Th17 cell differentiation) may be one of the mechanisms of the nerve in psoriasis. We suggest that the nerve may be a promising candidate target for psoriasis treatment, or a novel supplement to current therapies.

\section{Materials And Methods}

\section{Retrospective clinical cases review}

We collected the clinical cases of psoriasis with concomitant nerve injuries who were admitted to Department of Dermatology, Sichuan Provincial People's Hospital, or Department of Dermatology, Daping Hospital of Army Medical University (both up to September 2019). Their diagnoses of psoriasis were confirmed by a dermatologist at admission. Their medical records of peripheral or central nerve injuries and the development of psoriasis were reviewed by three independent dermatologists. In order to balance the variability of other factors (e.g. medications), psoriasis development on the side of nerve injuries was compared with that on the normal side.

\section{Literature review}

The database of PubMed and Google Scholar were used to retrieve psoriatic cases with nerve injuries published in literatures up to September 2019. Medical Subject Heading (MeSH) included "psoriasis" combined with "nerve", "trauma", "stroke", or "poliomyelitis". Only articles published in English were included.

\section{Mouse experiment design}

The experiments were performed under a protocol approved by Medical Ethics Committee in Sichuan Academy of Medical Sciences \& Sichuan Provincial People's Hospital. Forty female 4,5, 7-8 week (18$22 \mathrm{~g})$ C57/BL6J mice (wild-type) were acclimatized for 2 weeks before the experiment. They were maintained at room temperature of $22^{\circ} \mathrm{C}$, and with the cycles of $12 / 12$ hours of light and dark. 
Mice were randomized divided into two groups. For Group 1, on the day after the depilation, the right dorsal nerve was injured by surgery operation, and 5\% imiquimod cream (MED-SHINE Pharmaceutical Co., Ltd, China) was applied to both dorsal sides. For Group 2, after induction of psoriasiform dermatitis by imiquimod, surgery of right unilateral denervation was performed.

\section{Unilateral denervation surgery operation}

The hairs in the dorsal area of all mice were removed $(2.5 \mathrm{~cm} \times 2 \mathrm{~cm})$ with electric shaver and depilated with a depilatory cream (LAVER, Zhengzhou, China). The unilateral denervation surgery operation was referred to the method described in the literatures. ${ }^{5-7}$ Briefly, deplilated mice were anesthetized by pentobarbital sodium, and their dorsal skin was cut along the back midline, from the bottom of the neck to the $0.5 \mathrm{~cm}$ above the nail (about 2.5 to $3 \mathrm{~cm}$ ). The bilateral skin and subcutaneous tissue were bluntly separated, and the dorsal cutaneous nerves with white dendritic branch appearance (T3-12) were exposed. The nerves on the right side were cut and removed off, with the nerves on the other side as the sham-operation control (Supplementary material \#1 and \#2). Surgical tweezers were used to gently pinch the skin of both sides respectively to ensure the success of unilateral denervation surgery (Supplementary video). And immunofluorescence staining of anti-PGP 9.5 (protein gene product 9.5, a panneuronal marker) was performed to further demonstrate the successful intervention on the nerves.

\section{Induction of psoriasiform dermatitis}

Imiquimod-induced dermatitis has been the most widely used animal model of psoriasis since it was first published in $2009 .{ }^{21}$ Briefly, imiquimod cream $(5 \%, 6.25 \mathrm{mg}$ ) was applied symmetrically and evenly on the shaved dorsal area of each mouse once a day for continuous 7 days.

\section{Skin lesion score and histopathologic staining}

Comparison of the severity of psoriasiform dermatitis of right and left sides on the same mouse can reduce inter-individual differences. On the day of unilateral denervation and the 2nd, 4th, 6th, 8th day after the operation, mice were sacrificed by cervical dislocation. The skin lesions of both sides were photographed, and visually scored (redness score plus scaling score) by three independent dermatologists blinded to the side of denervation surgery. Redness score: none, 0 ; light red, 1 ; red not dark, 2; dark red, 3; extremely red, 4 . Scaling score: none, 0 ; thin scales with limited surface area, 1; thicker (mild) scales with modest surface area, 2; thick scales, rough, with larger surface area, 3 ; very robust scales with vast surface area, 4 . The tissues on both sides were collected and fixed in formalin solutions. Routine histopathologic staining of hematoxylin and eosin (HE) was performed according to standard procedures. The HE images were acquired with DS-U3 imaging system (Nikon, Japan). The epidermal thickness was measured by CaseViewer software (3DHISTECH, Hungary).

\section{Immunofluorescence staining}

The immunofluorescence staining was used to assess the nerve content in the skin lesions. Briefly, 4- $\mu \mathrm{m}$ sections of formalin-fixed paraffin embedded skin tissues were mounted on slides coated with poly-Llysine. After routine dewaxing, permeabilization, and blockage, diluted anti-PGP9.5 antibody (Abcam, MA, 
USA) was applied to the sections overnight at $4{ }^{\circ} \mathrm{C}$. After washing, diluted Cy3-conjugated goat antimouse antibody was applied onto the sections for $60 \mathrm{~min}$ at room temperature. Nuclei were counterstained for 5 min with 4', 6'-diamidino-2-phenylindole (DAPI, Sigma, USA). Images were obtained on a Nikon ECLIPSE fluorescence microscope with the SPOT Advanced ${ }^{\text {TM }}$ software (Diagnostics Instruments, USA). The relative quantification of the nerves was performed by software of Image-pro plus 6.0 (Media Cybernetics, USA).

\section{RNA sequencing and bioinformatics analysis}

Skin tissue samples on both sides of mice in Group1 and Group2 were collected for RNA-sequencing at 6th day after denervation surgery. Bioinformatics analyses were performed, including Gene Ontology (GO) enrichment analysis of identified the differentially expressed genes, and Kyoto Encyclopedia of Genes and Genomes (KEGG) pathway enrichment analysis (Supplementary material \#3).

\section{Statistical analysis}

The differences between lesions on the denervation and normal sides were determined with Student t-test by SPSS Statistics 17.0 (SPSS Inc., USA). P $<0.05$ was considered to be of statistical significance.

\section{Results}

\section{Clinical Case review}

Totally, twenty cases of psoriatic patients concomitantly suffered from nerve injuries were collected and reviewed. Seven from our clinical practice (Case 1-7, Fig. 1), and thirteen from published literatures (Case 8-20). ${ }^{8-20}$ All of them are summarized in Table 1. There were four females and sixteen males between the ages of 29 and $85(55.5 \pm 12.6)$. Sixteen suffered from peripheral nerve injuries, and four suffered from central nerve damages. Among the sixteen patients, six experienced nerve fiber injuries due to surgeries (two at the left knee, two at the right knee, one for mastectomy of the right breast cancer, one for amputation of the right forearm), five from poliomyelitis (two at the right lower limb, two at the left lower limb, one at the left upper limb), and other five suffered from traumas, including one dislocation of the right shoulder joint and one laceration of the left palm. The left four patients suffered from central nervous system damages because of cerebrovascular accidents, including stroke and subarachnoid hemorrhage. 
Table 1

Cases of psoriatic patients concomitantly suffered from the nerve injuries.

\begin{tabular}{|c|c|c|c|c|c|c|}
\hline Case & $\begin{array}{l}\text { Age/ } \\
\text { Sex }\end{array}$ & $\begin{array}{l}\text { Type/ } \\
\text { Psoriatic } \\
\text { History }\end{array}$ & $\begin{array}{l}\text { Site/ Cause of } \\
\text { Denervation }\end{array}$ & $\begin{array}{l}\text { Development of } \\
\text { Lesions }\end{array}$ & Recurrence & $\begin{array}{l}\text { Figure 1/ } \\
\text { Reference }\end{array}$ \\
\hline 1 & $\begin{array}{l}37 / \\
M\end{array}$ & $\begin{array}{l}\text { PV/ 10- } \\
\text { year }\end{array}$ & $\begin{array}{l}\text { Left knee/ Car } \\
\text { accident }\end{array}$ & $\begin{array}{l}\text { Psoriasis on left } \\
\text { knee and lower } \\
\text { limb cleared }\end{array}$ & No & Figure $1 \mathrm{~A}$ \\
\hline 2 & $\begin{array}{l}38 / \\
M\end{array}$ & $\begin{array}{l}\text { PV/ 3- } \\
\text { year }\end{array}$ & $\begin{array}{l}\text { Left lower limb/ } \\
\text { Poliomyelitis }\end{array}$ & $\begin{array}{l}\text { Psoriasis } \\
\text { developed sparing } \\
\text { the left leg }\end{array}$ & No & Figure 1B \\
\hline 3 & $\begin{array}{l}52 / \\
M\end{array}$ & $\begin{array}{l}\mathrm{PV/} 3- \\
\text { year }\end{array}$ & $\begin{array}{l}\text { Right knee/ } \\
\text { Trauma }\end{array}$ & $\begin{array}{l}\text { Psoriasis on the } \\
\text { right knee and right } \\
\text { lower limb relieved }\end{array}$ & Partial & Figure 1C \\
\hline 4 & $\begin{array}{l}56 / \\
M\end{array}$ & $\begin{array}{l}\text { PV/ 10- } \\
\text { year }\end{array}$ & $\begin{array}{l}\text { Right lower } \\
\text { limb/ } \\
\text { Poliomyelitis }\end{array}$ & $\begin{array}{l}\text { Psoriasis } \\
\text { developed on both } \\
\text { legs, with the right } \\
\text { alleviated }\end{array}$ & No & Figure 1D \\
\hline 5 & $\begin{array}{l}62 / \\
M\end{array}$ & $\begin{array}{l}\text { PP/ 5- } \\
\text { year }\end{array}$ & $\begin{array}{l}\text { Left little finger/ } \\
\text { Trauma }\end{array}$ & $\begin{array}{l}\text { Psoriasis on the } \\
\text { left little finger } \\
\text { relieved }\end{array}$ & Partial & Figure 1E \\
\hline 6 & $\begin{array}{l}55 / \\
M\end{array}$ & $\begin{array}{l}P V / 12- \\
\text { year }\end{array}$ & $\begin{array}{l}\text { Right forearm/ } \\
\text { Amputation }\end{array}$ & $\begin{array}{l}\text { Psoriasis on right } \\
\text { hand relieved }\end{array}$ & Partial & Figure 1F \\
\hline 7 & $\begin{array}{l}57 / \\
M\end{array}$ & $\begin{array}{l}\text { PP/ 7- } \\
\text { year }\end{array}$ & $\begin{array}{l}\text { Right hand/ } \\
\text { Trauma }\end{array}$ & $\begin{array}{l}\text { Psoriasis on the } \\
\text { right hand relieved }\end{array}$ & Partial & Figure 1G \\
\hline 8 & $\begin{array}{l}48 / \\
M\end{array}$ & $\begin{array}{l}\mathrm{PV} / 10- \\
\text { year }\end{array}$ & $\begin{array}{l}\text { Right knee/ } \\
\text { Surgery }\end{array}$ & $\begin{array}{l}\text { Psoriasis on right } \\
\text { knee cleared }\end{array}$ & Yes & $\begin{array}{l}\text { Dewing, } 1971 \\
8\end{array}$ \\
\hline 9 & $\begin{array}{l}72 / \\
F\end{array}$ & $\begin{array}{l}\text { PV and } \\
\text { PsA/ 10- } \\
\text { year }\end{array}$ & $\begin{array}{l}\text { Left arm/ } \\
\text { Poliomyelitis }\end{array}$ & $\begin{array}{l}\text { PsA developed } \\
\text { only on the right } \\
\text { hand }\end{array}$ & No & $\begin{array}{l}\text { Weiner et al., } \\
1985^{9}\end{array}$ \\
\hline 10 & $\begin{array}{l}53 / \\
F\end{array}$ & $\begin{array}{l}\text { PV and } \\
\text { PsA/ 1.5- } \\
\text { year }\end{array}$ & $\begin{array}{l}\text { Right breast/ } \\
\text { Mastectomy }\end{array}$ & $\begin{array}{l}\text { Psoriasis on the } \\
\text { right elbow and } \\
\text { palm cleared }\end{array}$ & Partial & $\begin{array}{l}\text { Ferber et al., } \\
1990^{10}\end{array}$ \\
\hline 11 & $\begin{array}{l}68 / \\
M\end{array}$ & $\begin{array}{l}\mathrm{PV} / 3- \\
\text { year }\end{array}$ & $\begin{array}{l}\text { Left knee/ } \\
\text { Surgery }\end{array}$ & $\begin{array}{l}\text { Psoriasis on left } \\
\text { leg cleared }\end{array}$ & No & $\begin{array}{l}\text { Raychaudhuri } \\
\text { and Afaerber, } \\
199311\end{array}$ \\
\hline 12 & $\begin{array}{l}49 / \\
M\end{array}$ & $\begin{array}{l}\text { PV/ } \\
\text { Prolonged }\end{array}$ & $\begin{array}{l}\text { Right shoulder/ } \\
\text { Dislocation }\end{array}$ & $\begin{array}{l}\text { Psoriasis on the } \\
\text { right forearm and } \\
\text { hand cleared }\end{array}$ & Yes & $\begin{array}{l}\text { Joseph et al., } \\
2005^{12}\end{array}$ \\
\hline
\end{tabular}

Abbreviations: F, female; $\mathrm{M}$, male; PV, psoriasis vulgaris; PP, pustule psoriasis; PsA, psoriatic arthritis. 


\begin{tabular}{|c|c|c|c|c|c|c|}
\hline Case & $\begin{array}{l}\text { Age/ } \\
\text { Sex }\end{array}$ & $\begin{array}{l}\text { Type/ } \\
\text { Psoriatic } \\
\text { History }\end{array}$ & $\begin{array}{l}\text { Site/ Cause of } \\
\text { Denervation }\end{array}$ & $\begin{array}{l}\text { Development of } \\
\text { Lesions }\end{array}$ & Recurrence & $\begin{array}{l}\text { Figure 1/ } \\
\text { Reference }\end{array}$ \\
\hline 13 & $\begin{array}{l}60 / \\
F\end{array}$ & $\begin{array}{l}\mathrm{PV/} \text { 44- } \\
\text { year } \\
\text { PsA/ 15- } \\
\text { year }\end{array}$ & $\begin{array}{l}\text { Left palm/ } \\
\text { Laceration }\end{array}$ & $\begin{array}{l}\text { PsA developed in } \\
\text { all fingers on left } \\
\text { hand except the } \\
\text { lacerated one }\end{array}$ & Yes & $\begin{array}{l}\text { Kane et al., } \\
2005^{13}\end{array}$ \\
\hline 14 & $\begin{array}{l}29 / \\
M\end{array}$ & $\begin{array}{l}\text { PV/ 7- } \\
\text { year }\end{array}$ & $\begin{array}{l}\text { Left lower limb/ } \\
\text { Poliomyelitis }\end{array}$ & $\begin{array}{l}\text { Psoriasis } \\
\text { developed sparing } \\
\text { the left leg }\end{array}$ & No & $\begin{array}{l}\text { Ravikumar } \\
\text { and } \\
\text { Sinhasan, } \\
2014^{14}\end{array}$ \\
\hline 15 & $\begin{array}{l}67 / \\
M\end{array}$ & $\begin{array}{l}\text { PV/ 10- } \\
\text { year }\end{array}$ & $\begin{array}{l}\text { Left lower limb/ } \\
\text { Poliomyelitis }\end{array}$ & $\begin{array}{l}\text { Psoriasis } \\
\text { developed sparing } \\
\text { the left leg }\end{array}$ & No & $\begin{array}{l}\text { Wang and } \\
\text { Tsai, } 2014{ }^{15}\end{array}$ \\
\hline 16 & $\begin{array}{l}51 / \\
M\end{array}$ & $\begin{array}{l}\text { Nail } \\
\text { psoriasis/ } \\
\text { Prolonged }\end{array}$ & $\begin{array}{l}\text { Right upper } \\
\text { arm/ Trauma }\end{array}$ & $\begin{array}{l}\text { Psoriasis on the } \\
\text { right hand cleared } \\
\text { except the first } \\
\text { fingernail }\end{array}$ & No & $\begin{array}{l}\text { Kecici et al., } \\
2017^{16}\end{array}$ \\
\hline 17 & $\begin{array}{l}59 / \\
F\end{array}$ & $\begin{array}{l}\text { PV/ 7- } \\
\text { month }\end{array}$ & $\begin{array}{l}\text { Right } \\
\text { hemiplegia/ } \\
\text { Subarachnoid } \\
\text { hemorrhage }\end{array}$ & $\begin{array}{l}\text { Psoriasis only } \\
\text { developed on the } \\
\text { right limb }\end{array}$ & No & $\begin{array}{l}\text { Veale et al., } \\
1993^{17}\end{array}$ \\
\hline 18 & $\begin{array}{l}62 / \\
M\end{array}$ & $\begin{array}{l}\mathrm{PV} / 6- \\
\text { month }\end{array}$ & $\begin{array}{l}\text { Left } \\
\text { hemiparesis/ } \\
\text { Cerebrovascular } \\
\text { accident }\end{array}$ & $\begin{array}{l}\text { Psoriasis only } \\
\text { developed on the } \\
\text { right extremities }\end{array}$ & Partial & $\begin{array}{l}\text { Sowell et al., } \\
1993^{18}\end{array}$ \\
\hline 19 & $\begin{array}{l}85 \\
/ F\end{array}$ & $\begin{array}{l}\text { PV/ 40- } \\
\text { year }\end{array}$ & $\begin{array}{l}\text { Confused state/ } \\
\text { Cerebrovascular } \\
\text { accident }\end{array}$ & $\begin{array}{l}\text { Psoriasis on most } \\
\text { parts of the body } \\
\text { cleared }\end{array}$ & Partial & $\begin{array}{l}\text { Stratigos et } \\
\text { al., } 1998{ }^{19}\end{array}$ \\
\hline 20 & $\begin{array}{l}52 / \\
M\end{array}$ & $\begin{array}{l}\text { PV/ } \\
\text { unknown }\end{array}$ & $\begin{array}{l}\text { Left } \\
\text { hemiparesis/ } \\
\text { Stroke }\end{array}$ & $\begin{array}{l}\text { Psoriasis almost } \\
\text { completely cleared }\end{array}$ & No & $\begin{array}{l}\text { Lee EB et al., } \\
2019^{20}\end{array}$ \\
\hline
\end{tabular}

In all cases (20/20), we found that the local lesions under the control of injured nerves spontaneously relieved or even cleared/spared. In detail, for patients whose nerve injuries occurred after their psoriasis, the nerve injuries made the local psoriatic lesions spontaneously relieved (5/15) or cleared (10/15). For patients suffered from early poliomyelitis prior to their psoriasis, poliomyelitis spared their psoriasis on the affected limb (4/5), or alleviate it (1/5). Only $35 \%(7 / 20)$ patients experienced partial recurrence of psoriatic lesions, most likely due to regaining of nerve functions.

\section{Skin denervation led to the attenuation of cutaneous innervation}


Unilateral denervation on mice with the other side as control can avoid the influence of individual differences on experimental results. The successful attenuation of nerve function in the skin following denervation surgery was confirmed by pinching the skin lesions with surgical tweezers. For the pinching on the control side, mice turned their heads or shook when stimulated by pain, while for the side of unilateral denervation, the response was weakened or absent (Supplementary video). The attenuation of cutaneous nerve function was further confirmed by immunofluorescence staining of PGP 9.5. The denervation surgery side (Right) showed less PGP9.5 positive nerve fibers than the sham-operation control side (Left) under the induction of imiquimod at 4th, 6th, and 8th day $(P=0.038, P<0.01$, and $P<$ 0.01 , respectively. Figure $2 \mathrm{~A}$ and $\mathrm{C}$ ).

The unilateral denervation prior to the application of imiquimod interfered with the induction of ipsilateral psoriasiform dermatitis

In Group1, we found that daily application of imiquimod could remarkably increase cutaneous nerves on the normal side (Left, 2nd day, $P=0.057$; 6 th day, $P<0.001$, compared with day 0 ), while failed on the denervation side (Right, Fig. 2A and C). It was shown that the erythema and scale on the dorsal skin began to appear on the second day of imiquimod application. They became more obvious with daily application of imiquimod, and declined from the 8th day for both sides (Fig. 3A). However, the scores of lesions on the denervation side (Right) were significantly lower than those on the normal side of left (6th day, $\mathrm{P}<0.001 ; 8$ th day, $\mathrm{P}=0.044$, Fig. $3 \mathrm{C}$ ). These demonstrated that the denervation interfered with the induction of psoriasiform dermatitis, which was further supported by HE stainings of the lesions (Fig. 3B). The epidermis thicknesses of imiquimod-induced lesions on the denervation side (Right) were thinner than those on the normal side of left (2nd day, $P=0.006$; 4th day, $P=0.003$; 6th day, $P<0.001$, Fig. 3D).

\section{The unilateral denervation after the induction of psoriasiform dermatitis could promote the recovery of ipsilateral lesions}

In Group2, after the termination of imiquimod on psoriasiform dermatitis, the increased nerves gradually returned to normal level, with strikingly less nerves on the denervation side (Right) than those on the normal side of left ( 2 nd day, $P<0.001 ; 4$ th day, $P=0.017$. Figure $2 B$ and $D$ ). We demonstrated the erythema and scale of psoriasiform lesions gradually decreased for both sides with the progress of time after imiquimod termination (Fig. 4A). However, the denervation side (Right) relieved faster than the normal side (Left), supported by its significantly lower scores (2nd day, $P<0.001$; 6th day, $P<0.001$; 8th day, $P=0.017$, Fig. 4 C). Similarly, histopathological results showed that the lesion epidermis thickness was markedly thinner on the denervation side (Right) than the normal side of left (2nd day, $P=0.001 ; 4$ th, 6th and 8th day, $P<0.001$, respectively. Figure $4 B$ and $D$ ).

The unilateral denervation prior to the application of imiquimod interfered with the enhancement of inflammatory reactions 
In Group1, imiquimod application could increase inflammatory reactions on both sides. However, it showed that the denervation (Right) interfered with induced inflammatory reactions analyzed by bioinformatics analysis of GO and KEGG. As illustrated in Fig. 5, the enhancement of inflammatory reactions on the denervation side (Right) was significantly weaker than that on the normal side (Left), including acute inflammatory response and cellular response to IL-1 $(P<0.01, P=0.01$, respectively, Fig. 5A), and antigen processing and presentation, Th17 cell differentiation pathway (both $P=0.04$, Fig. 5B).

\section{The unilateral denervation after the induction of psoriasiform dermatitis promoted the regression of inflammatory reactions}

In Group2, inflammatory reactions gradually subsided after termination of imiquimod on both sides. However, denervation surgery on the right side could remarkably promote the regression of inflammatory reactions. $G O$ and KEGG analyses showed that the responses of $T$ cell activation $(P=0.05)$, antigen processing/presentation $(P=0.02)$, and response to IL-1 $(P=0.01)$ in Fig. $5 \mathrm{C}$, and also pathways of TNF signaling $(P<0.01)$, Toll-like receptor signaling $(P<0.01)$, Natural killer cell mediated cytotoxicity $(P<$ $0.01)$, Th17 cell differentiation $(P=0.02)$, Th1 and Th2 cell differentiation $(P=0.01)$, and neurotrophin signaling $(P=0.04)$ in Fig. 5D on the denervation side were significantly decreased, compared with the normal side.

\section{Discussion}

Psoriasis is a chronic skin inflammation. Immunological mechanisms play a pivotal role in its pathogenesis, and recent clinical practices have demonstrated the effectiveness of biological antibodies targeting dysregulated cytokines in psoriasis, especially interleukin-17A. ${ }^{22}$ On the other hand, as the largest organ of our body, the skin contains abundant nerve fibers, which are densely distributed in various layers of the skin. They communicate with various skin cell groups by releasing neuropeptides, and almost all of the skin cells express receptors for neuropeptides. Meanwhile, the stimulated skin cells also can produce neuropeptides, which in turn act on the nerves. It is such bidirectional communication creates feedback loops in chronic inflammatory skin diseases. ${ }^{23}$

There are increasing observations supporting the direct or indirect participation of the nerve in psoriasis development. (1) The stimulation of the nerves (e.g. herpes zoster) can induce or aggravate psoriasis, most likely through Koebner phenomenon. ${ }^{24}$ We add here a representative case of thigh psoriasis aggravated by herpes zoster at the same site (more details in supplementary material \#4). (2) A series of early histological studies indicated that the nerve fibers, Schwann cells and other nerve supporting cells in psoriatic lesions were remarkably elevated than the normal skin. ${ }^{25}$ Moreover, results have confirmed the significant increase of nerve fibers in both imiquimod-induced psoriasiform dermatitis (Fig. 2A and C) and the severe combined immunodeficient mouse-human skin model. ${ }^{26}$ (3) Reduced large fiber 
functioning and altered small fiber functioning in psoriasis have been demonstrated, and there is upregulation of neuropeptides released by sensory nerve cells that innervate psoriatic lesions. ${ }^{23,27,28}$ (4) Trigger factors of psoriasis can upregulate and activate some receptors and ion channels on sensory nerves, leading to neurogenic inflammation and pruritus in psoriasis. ${ }^{23,29}(5)$ Several tentative therapies, including dermatiome-shaving, capsaicin cream, resiniferatoxin, onabotulinumtoxinA, and K252a (a highaffinity nerve growth factor receptor blocker), can improve psoriasis or psoriasiform dermatitis, through reducing lesional nerve fibers or sensory denervation. ${ }^{30-36}$ And nerve blockade based on locoregional anaesthesia has been proposed in psoriasis treatment. ${ }^{37,38}(6)$ Sporadic case reports of psoriasis spared or alleviated in the site of nerve injured (e.g. poliomyelitis, trauma) provide direct evidences for the roles of the nerve in psoriasis development. ${ }^{12,14,15}$

In this study, we further analyzed case collections of psoriatic patients who complicated with nerve injury in two hospitals and such cases from published literatures. We found that $100 \%$ local lesions under the control of the injured nerves spontaneously relieved or even cleared/spared. For patients whose nerve injuries happened after their psoriasis, the nerve injuries relieved (33\%) or cleared $(67 \%)$ their local psoriatic lesions. And for psoriatic patients with early poliomyelitis, poliomyelitis spared their psoriasis on the affected limb ( $80 \%)$, or alleviate it $(20 \%)$. Only about one third patients experienced partial recurrence of psoriatic lesions, probably with the regaining of their nerve functions. This analysis further support the involvement of the nerve in psoriasis.

With these clinical cases alone, the conclusion that the nerve is involved in psoriasis cannot be fully drawn. Therefore, on the basis of these clinical observations, we further solidified the conclusion with mouse psoriasiform models. Based on the levels of lesion scores and histopathological changes, we demonstrated that the unilateral denervation surgery prior to the application of imiquimod interfered the enhancement of inflammatory reactions (e.g. adaptive immune response and Th17 cell differentiation pathway) and the induction of ipsilateral psoriasiform dermatitis. Moreover, the unilateral denervation after the induction of psoriasiform dermatitis could promote the regression of inflammatory reactions (e.g. T cell activation, TNF signaling, and Th17 cell differentiation pathway) and the recovery of ipsilateral dermatitis. Thus we solid the contribution of the nerve in the development of psoriasiform dermatitis from two aspects, unilateral denervation before and after the induced dermatitis respectively. This research design is based on clinical observations (e.g. peripheral nerve trauma, poliomyelitis), and there are no such studies based on both two aspects in previous literatures. Moreover, our results from wildtype mice, not transgenic mice, can better imitate clinical practice. We also performed the above experiments on wild-type BABL/C mice in order to avoid the possible influence of strain differences, and we obtained consistent results (data not shown).

The involvement of the nerve in psoriasis development have long been explored. Firstly, the upregulated neuropeptides released by sensory nerve in psoriatic lesions, such as substance $\mathrm{P}(\mathrm{SP})$, calcitonin gene related protein (CGRP), nerve growth factor (NGF), vasoactive intestinal peptide (VIP), can interact with various types of skin cells, including keratinocytes, endothelial cells, and mast cells. ${ }^{39}$ For example, SP, 
NGF and VIP can induce the degranulation of mast cells, and promote keratinocyte and endothelial cell hyperproliferation; ${ }^{40-42}$ CGRP cooperates with SP to induce the vasodilation and various pruritus/pain states. ${ }^{43}$ More importantly, the use of neuropeptide receptor antagonist improved the psoriasiform dermatitis in the transgenic KC-Tie2 mouse model, and SP and CGRP receptor agonist administration into denervated mouse skin resumed keratinocyte hyperproliferation in a neuropeptide specific manner. ${ }^{6}$ Secondly, the dynamic neuronal-immune system cross-talk has been implicated in various chronic inflammations. ${ }^{44,45}$ Upon infections and chronic inflammations, the nerve can control immune molecular cascades from dendritic cells, T cells, mast cells or keratinocytes, leading to activation of innate and adaptive immune system. On the other hand, immune chemokines and cytokines (e.g. Th2 type IL-4, IL-5, and IL-13) can trigger the activation of sensory fibers to coordinate host-protective behavioral responses. $^{23,29,44}$ It has been demonstrated that, based on transgenic KC-Tie2 mouse model of psoriasiform dermatitis, nervous interventions of surgical denervation, neuropeptide blocker, and botulinum neurotoxin A injection can significantly decrease IL-23, CD4 + T cells, especially CD11 + dendritic cells, along with the improvement of psoriatic acanthosis. ${ }^{6,46}$ With wild-type mice, here we demonstrated here that unilateral denervation surgery remarkably decreased Th17 cell differentiation, TNF signaling, Toll-like receptor signaling, Th1 and Th2 cell differentiation, and JAK-STAT signaling pathways on ipsilateral side. Together, relationship between the nervous and immune systems in psoriasis have been recognized, however the precise underlying mechanisms are just starting to be elucidated.

It is noteworthy that psoriasiform lesions on the denervated side of mouse were not extremely relieved as expected. Similar phenomena also can be observed in clinical cases in Fig. 1C and 1D. Moreover, very few mice in this study were found to delay the recovery of psoriasiform dermatitis by denervation surgery (Supplementary material \#5). These observations suggest that the nerve may not work alone in psoriasis development. Alternatively there may be dysregulated compensatory repair mechanisms of the nerves (e.g. over-repair), or repair divergence of different types of nerves (sensory, autonomic and motor) that may play distinct functions in the balance of skin neuroimmune ${ }^{47,48}$. These observations suggest the complexity of neuroimmune regulation in psoriasis.

Limitations of this study are (1) The collateral reinnervation of the nerves in the dorsal skin of mice limits the longer-period investigation; (2) Hair re-growth (approximately 10th day after the depilation) on the back also limits longer-period observation; (3) Imiquimod-induced dermatitis has been the most widely used animal model of psoriasis, however it is different in terms of psoriatic pathogenesis to some extent.

\section{Conclusion}

In summary, our study based on both retrospective clinical case review and mouse-based experiments provide multiple evidence for the involvement of the nerve in psoriasis development. Regulation of immune events (e.g TNF signaling and Th17 cell differentiation pathway) may be one of the mechanisms of the nerve in psoriasis. Recent research has demonstrated low-intensity electroacupuncture stimulation 
of the nerve can repress endotoxin-induced systemic inflammation in mice. ${ }^{49}$ Thus the nerve being a novel promising therapeutic target may be a beneficial supplement to current treatment strategies in psoriasis, which needs further investigations, especially the type of the nerves intervened and safe methods of intervention.

\section{Abbreviations}

HE: Hematoxylin-eosin; TNF:Tumor necrosis factor; Th:T helper cell; IL:Interleukin; MeSH:Medical Subject Heading; PGP 9.5:Protein gene product 9.5; GO:Gene Ontology; KEGG:Kyoto Encyclopedia of Genes and Genomes; SP:Substance P, CGRP:Calcitonin gene related protein; NGF:Nerve growth factor, VIP:Vasoactive intestinal peptide; Fig.:Figure.

\section{Declarations}

\section{Availability of data and materials}

All data used and/or analyzed during this study are available on reasonable request from the corresponding author.

\section{Ethical Approval and Consent to participate}

The experiments in this study was approved by Medical Ethics Committee in Sichuan Academy of Medical Sciences \& Sichuan Provincial People's Hospital( NO:187/2019)

\section{Consent for publication}

Not applicable.

\section{Competing interests}

The authors declare no competing interest.

\section{Funding}

National Natural Science Foundation of China (No. 81771783, 81371729), Clinical research and translation key project of Sichuan Academy of Medical Sciences \& Sichuan Provincial People's Hospital (No. 2016LZ02), and Sichuan Science and Technology Program (No. 2019JDTD0027).

\section{Authors' contributions}


Bi Qin contributed to literature search, operation in experiments, data analysis, statistical analysis, and drafting of the manuscript; Chaonan Sun contributed to operation in experiments and data analysis; Ling Chen contributed to conception of the study, literature search, and critical revision of the manuscript; Siyu Wang contributed to literature search and critical revision of the manuscript; Jianing Yang contributed to operation in experiments; Zhen Xie contributed to data interpretation, and literature search; Zhu Shen contributed to conception and design of the study, literature search, data collection, and critical revision of the manuscript.

\section{Acknowledgements}

We would like to thank Dr. Jin Zhang for providing the clinical case of thigh psoriasis aggravated by his herpes zoster. The patients in this manuscript have given written informed consent to publication of their case details. This study was supported by National Natural Science Foundation of China (No. 81771783, 81371729), Clinical research and translation key project of Sichuan Academy of Medical Sciences \& Sichuan Provincial People's Hospital (No. 2016LZ02), and Sichuan Science and Technology Program (No. 2019JDTD0027).

\section{References}

1. Chen L, Shen Z. Tissue-resident memory $T$ cells and their biological characteristics in the recurrence of inflammatory skin disorders. Cell Mol Immunol. 2020;17(1):64-75.

2. Paul C, Lacour JP, Tedremets L, Kreutzer K, Jazayeri S, Adams S, et al. Efficacy, safety and usability of secukinumab administration by autoinjector/pen in psoriasis: a randomized, controlled trial (JUNCTURE). J Eur Acad Dermatol Venereol. 2015;29(6):1082-90.

3. Zhu TH, Nakamura M, Farahnik B, et al. The Role of the Nervous System in the Pathophysiology of Psoriasis: A Review of Cases of Psoriasis Remission or Improvement Following Denervation Injury. Am J Clin Dermatol. 2016;17(3):257-63.

4. Kim CH, Yoo JK, Jeon SH, Lim CY, Lee JH, Koo DB, et al. Anti-psoriatic effect of myeloid-derived suppressor cells on imiquimod-induced skin inflammation in mice. Scand J Immunol. 2019;89(3):e12742.

5. Onderdijk AJ, Hekking-Weijma IM, Florencia EF, Prens EP. Surgical Denervation in the ImiquimodInduced Psoriasiform Mouse Model. Methods Mol Biol. 2017;1559:75-81.

6. Ostrowski SM, Belkadi A, Loyd CM, Diaconu D, Ward NL. Cutaneous denervation of psoriasiform mouse skin improves acanthosis and inflammation in a sensory neuropeptide-dependent manner. J Invest Dermatol. 2011;131(7):1530-8.

7. Peterson SC, Brownell I, Wong SY. Cutaneous Surgical Denervation: A Method for Testing the Requirement for Nerves in Mouse Models of Skin Disease. J Vis Exp. 2016; (112): 54050.

8. Dewing SB. Remission of psoriasis associated with cutaneous nerve section. Arch Dermatol. 1971;104(2):220-1. 
9. Weiner SR, Bassett LW, Reichman RP. Protective effect of poliomyelitis on psoriatic arthritis. Arthritis Rheum. 1985;28(6):703-6.

10. Farber EM, Lanigan SW, Boer J. The role of cutaneous sensory nerves in the maintenance of psoriasis. Int J Dermatol. 1990;29(6):418-20.

11. Raychaudhuri SP, Farber EM. Are sensory nerves essential for the development of psoriatic lesions? J Am Acad Dermatol. 1993;28(3):488-9.

12. Joseph T, Kurian J, Warwick DJ, Friedmann PS. Unilateral remission of psoriasis following traumatic nerve palsy. Br J Dermatol. 2005;152(1):185-6.

13. Kane D, Lockhart JC, Balint PV,et al. Protective effect of sensory denervation in inflammatory arthritis (evidence of regulatory neuroimmune pathways in the arthritic joint). Ann Rheum Dis. 2005;64(2):325-7.

14. Ravikumar B, Sinhasan. Psoriasis sparing the polio-affected limb: is it merely the koebner phenomenon? Indian J Dermatol. 2014;59(5):505-6.

15. Wang TS, Tsai TF. Psoriasis sparing the lower limb with postpoliomyelitis residual paralysis. $\mathrm{Br} \mathrm{J}$ Dermatol. 2014;171(2):429-31.

16. Kecici AS, Goktay F, Tutkavul K, Gunes P, Yasar S. Unilateral improvement of nail psoriasis with denervation injury. Clin Exp Dermatol. 2018;43(3):339-41.

17. Veale D, Farrell M, Fitzgerald O. Mechanism of joint sparing in a patient with unilateral psoriatic arthritis and a longstanding hemiplegia. Br J Rheumatol. 1993;32(5):413-6.

18. Sowell JK, Pippenger MA, Crowe MJ. Psoriasis contralateral to hemiparesis following cerebrovascular accident. Int J Dermatol. 1993;32(8):598-9.

19. Stratigos AJ, Katoulis AK, Stavrianeas NG. Spontaneous clearing of psoriasis after stroke. J Am Acad Dermatol. 1998;38(5 Pt 1):768-70.

20. Lee EB, Reynolds KA, Pithadia DJ, Thiyanaratnam J, Wu JJ. Clearance of psoriasis after ischemic stroke. Cutis. 2019;103(2):74-6.

21. van der Fits L, Mourits S, Voerman JS, Kant M, Boon L, Laman JD, et al. Imiquimod-induced psoriasis-like skin inflammation in mice is mediated via the IL-23/IL-17 axis. J Immunol. 2009;182(9):5836-45.

22. Prinz I, Sandrock I, Mrowietz U. Interleukin-17 cytokines: Effectors and targets in psoriasis-A breakthrough in understanding and treatment. J Exp Med. 2020;217(1):e20191397.

23. Ayasse MT, Buddenkotte J, Alam M, Steinhoff M. Role of Neuroimmune Circuits and Pruritus in Psoriasis. Exp Dermatol. 2020;29(4):414-26.

24. Zhao YK, Zhang YQ, Wang F,et al. Developing Shingles-Induced Koebner Phenomenon in a Patient With Psoriasis: A Case Report. Medicine (Baltimore). 2015;94(26):e1009.

25. Weddell G, Cowan MA, Palmer E, Ramaswamy S. PSORIATIC SKIN. Arch Dermatol. 1965;91:252-66.

26. Sakai K, Sanders KM, Youssef MR, et al. Role of neurturin in spontaneous itch and increased nonpeptidergic intraepidermal fiber density in a mouse model of psoriasis. Pain. 
2017;158(11):2196-202.

27. Baumbach P, Weiss T, Giermann C, Cubillos S, Meissner W, Norgauer J. Standardized quantitative sensory testing in patients with psoriasis vulgaris: evidence for altered large and small fibre functioning. J Eur Acad Dermatol Venereol. 2016;30(11):e137-40.

28. Naukkarinen A, Nickoloff BJ, Farber EM. Quantification of cutaneous sensory nerves and their substance P content in psoriasis. J Invest Dermatol. 1989;92(1):126-9.

29. Trier AM, Mack MR, Kim BS. The Neuroimmune Axis in Skin Sensation, Inflammation, and Immunity. J Immunol. 2019;202(10):2829-35.

30. Elberg JJ, Brandrup F. Dermatome shaving of psoriasis. Br J Dermatol. 1987;117(6):745-50.

31. Momsen $\mathrm{OH}$, Kiil J. Dermatome-shaving of psoriasis. 7 years of experience. Ugeskr Laeger. 1994;156(47):7011-4.

32. Jancso G, Kiraly E, Jancso-Gabor A. Pharmacologically induced selective degeneration of chemosensitive primary sensory neurones. Nature. 1977;270(5639):741-3.

33. Riol-Blanco L, Ordovas-Montanes J, Perro M,et al. Nociceptive sensory neurons drive interleukin-23mediated psoriasiform skin inflammation. Nature. 2014;510(7503):157-61.

34. Saber M, Brassard D, Benohanian A. Inverse psoriasis and hyperhidrosis of the axillae responding to botulinum toxin type A. Arch Dermatol. 2011;147(5):629-30.

35. Aschenbeck KA, Hordinsky MK, Kennedy WR, et al. Neuromodulatory treatment of recalcitrant plaque psoriasis with onabotulinumtoxinA. J Am Acad Dermatol. 2018;79(6):1156-9.

36. Raychaudhuri SP, Sanyal M, Weltman H, Kundu-Raychaudhuri S. K252a, a high-affinity nerve growth factor receptor blocker, improves psoriasis: an in vivo study using the severe combined immunodeficient mouse-human skin model. J Invest Dermatol. 2004;122(3):812-9.

37. Jackson M, Bird J, Fearfield L. Neuroaxial blockade and psoriasis. Int J Obstet Anesth. 2008;17(1):80-1.

38. Kretz V, Vial F, Michel D, Bousquet S, Bouaziz H. Locoregional anaesthesia and psoriasis. Ann Fr Anesth Reanim. 2007;26(6):615-6.

39. Steinhoff M, Stander S, Seeliger S,et al. Modern aspects of cutaneous neurogenic inflammation. Arch Dermatol. 2003;139(11):1479-88.

40. Choi JE, Di Nardo A. Skin neurogenic inflammation. Semin Immunopathol. 2018;40(3):249-59.

41. Darsow U, Ring J. Neuroimmune interactions in the skin. Curr Opin Allergy Clin Immunol. 2001;1(5):435-9.

42. Raychaudhuri SP, Jiang WY, Raychaudhuri SK. Revisiting the Koebner phenomenon: role of NGF and its receptor system in the pathogenesis of psoriasis. Am J Pathol. 2008;172(4):961-71.

43. Schlereth T, Schukraft J, Krämer-Best HH, et al. Interaction of calcitonin gene related peptide (CGRP) and substance P (SP) in human skin. Neuropeptides. 2016;59:57-62.

44. Veiga-Fernandes $\mathrm{H}$, Artis D. Neuronal-immune system cross-talk in homeostasis. Science. 2018;359(6383):1465-6. 
45. Voisin T, Bouvier A, Chiu IM. Neuro-immune interactions in allergic diseases: novel targets for therapeutics. Int Immunol. 2017;29(6):247-61.

46. Ward NL, Kavlick KD, Diaconu D,et al. Botulinum neurotoxin A decreases infiltrating cutaneous lymphocytes and improves acanthosis in the KC-Tie2 mouse model. J Invest Dermatol. 2012;132(7):1927-30.

47. Riol-Blanco L, Ordovas-Montanes J, Perro M, Naval E, Thiriot A, Alvarez D, et al. Nociceptive sensory neurons drive interleukin-23-mediated psoriasiform skin inflammation. Nature. 2014;510(7503):15761.

48. Odoardi F, Neuhuber W, Flügel A. Pain-induced skin autoimmunity. Cell Res. 2014;24(9):1021-2. 49. Liu S, Wang ZF, Su YS, Ray RS, Jing XH, Wang YQ, et al. Somatotopic Organization and Intensity Dependence in Driving Distinct NPY-Expressing Sympathetic Pathways by Electroacupuncture. Neuron. 2020: S0896-6273(20)30532-8.

\section{Figures}
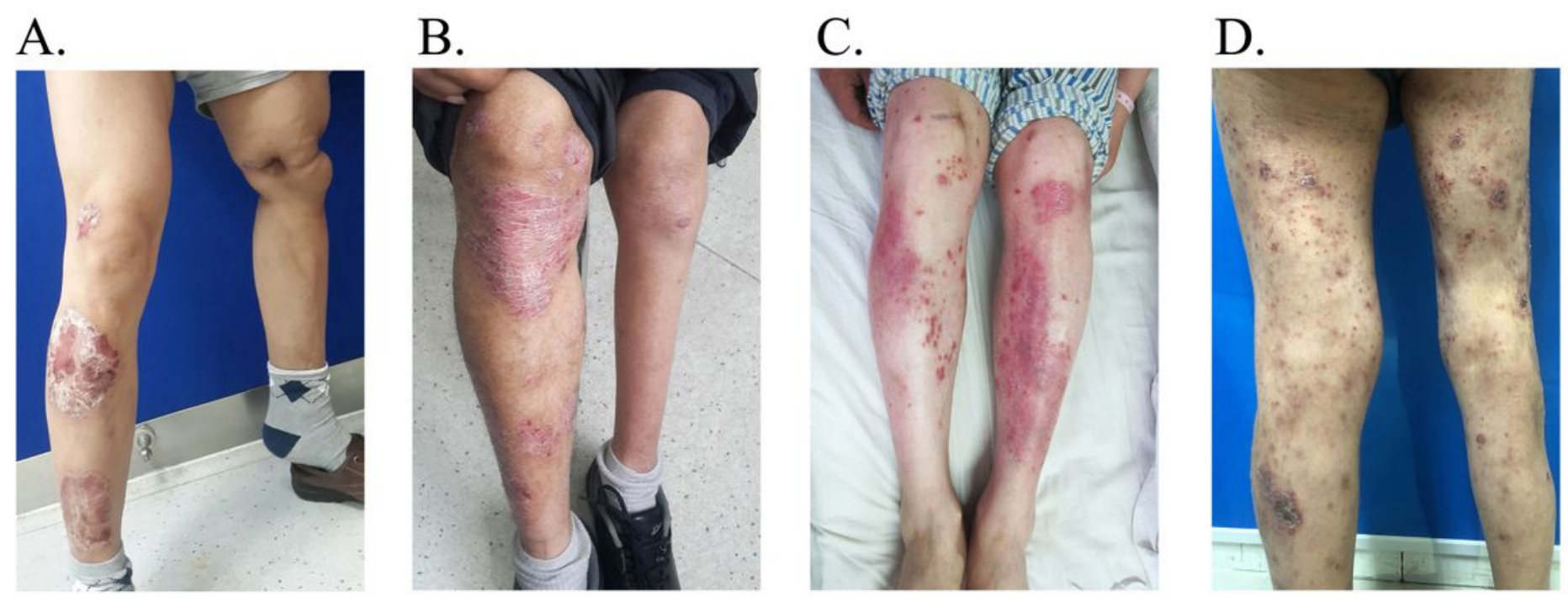

E.

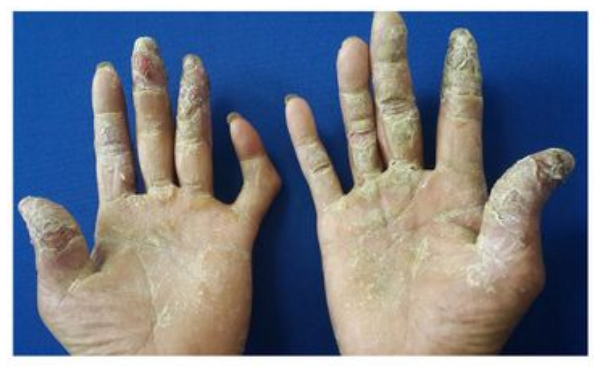

F.

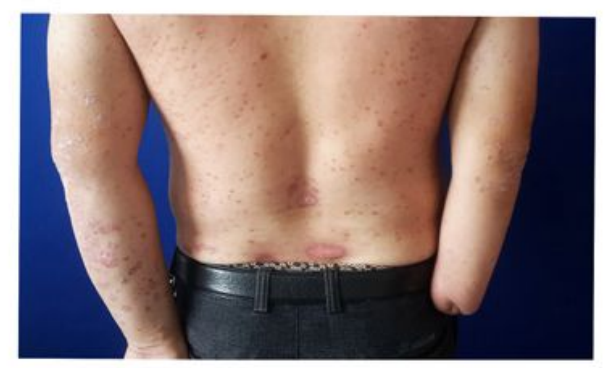

G.

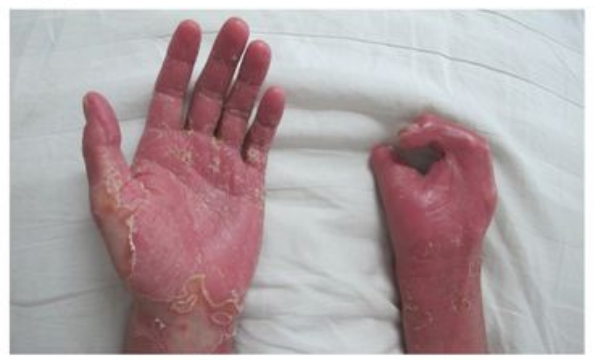

Figure 1 
Cases of psoriatic patients in our clinical practice concomitantly suffered from the nerve injuries. A: Left knee injured by a car accident; B: Left lower limb suffered from poliomyelitis; C: Right knee injured by a trauma; D: Right lower limb suffered from poliomyelitis; E: Left little finger injured by a trauma; F: Right forearm suffered from an amputation; G: Right hand injured by a trauma. More details in Table 1.
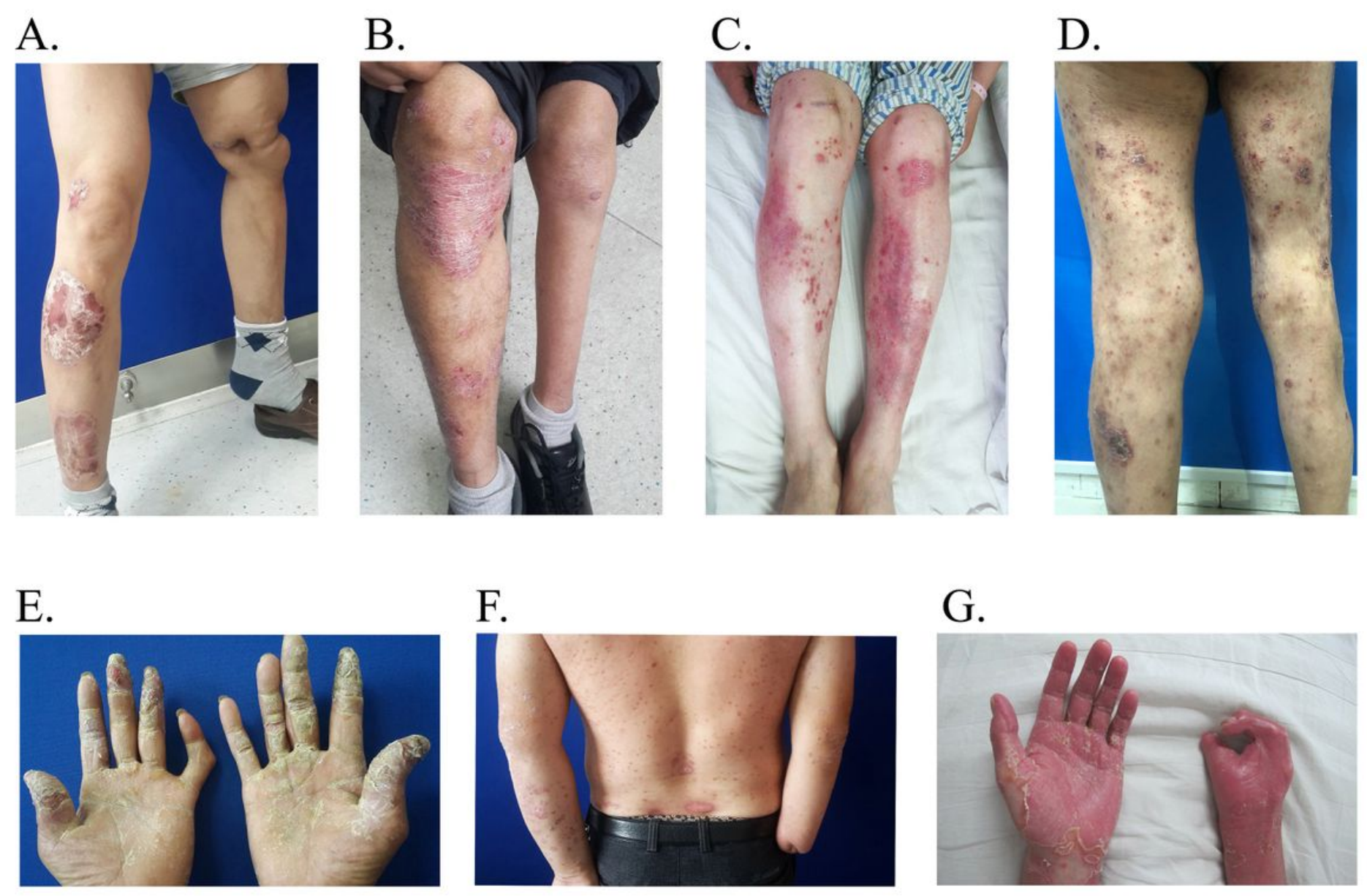

\section{Figure 1}

Cases of psoriatic patients in our clinical practice concomitantly suffered from the nerve injuries. A: Left knee injured by a car accident; B: Left lower limb suffered from poliomyelitis; C: Right knee injured by a trauma; D: Right lower limb suffered from poliomyelitis; E: Left little finger injured by a trauma; F: Right forearm suffered from an amputation; G: Right hand injured by a trauma. More details in Table 1. 

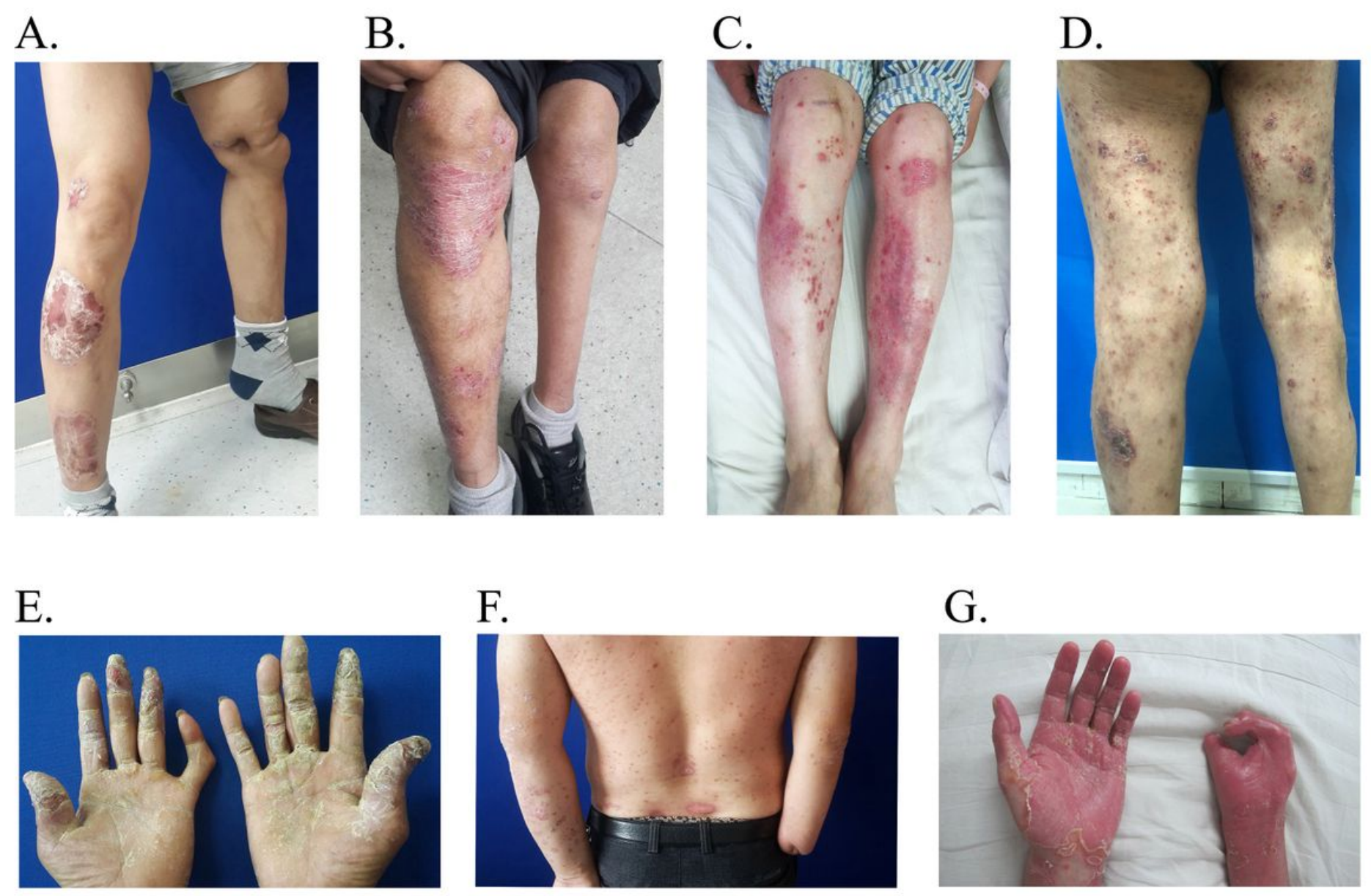

\section{Figure 1}

Cases of psoriatic patients in our clinical practice concomitantly suffered from the nerve injuries. A: Left knee injured by a car accident; B: Left lower limb suffered from poliomyelitis; C: Right knee injured by a trauma; D: Right lower limb suffered from poliomyelitis; E: Left little finger injured by a trauma; F: Right forearm suffered from an amputation; G: Right hand injured by a trauma. More details in Table 1. 

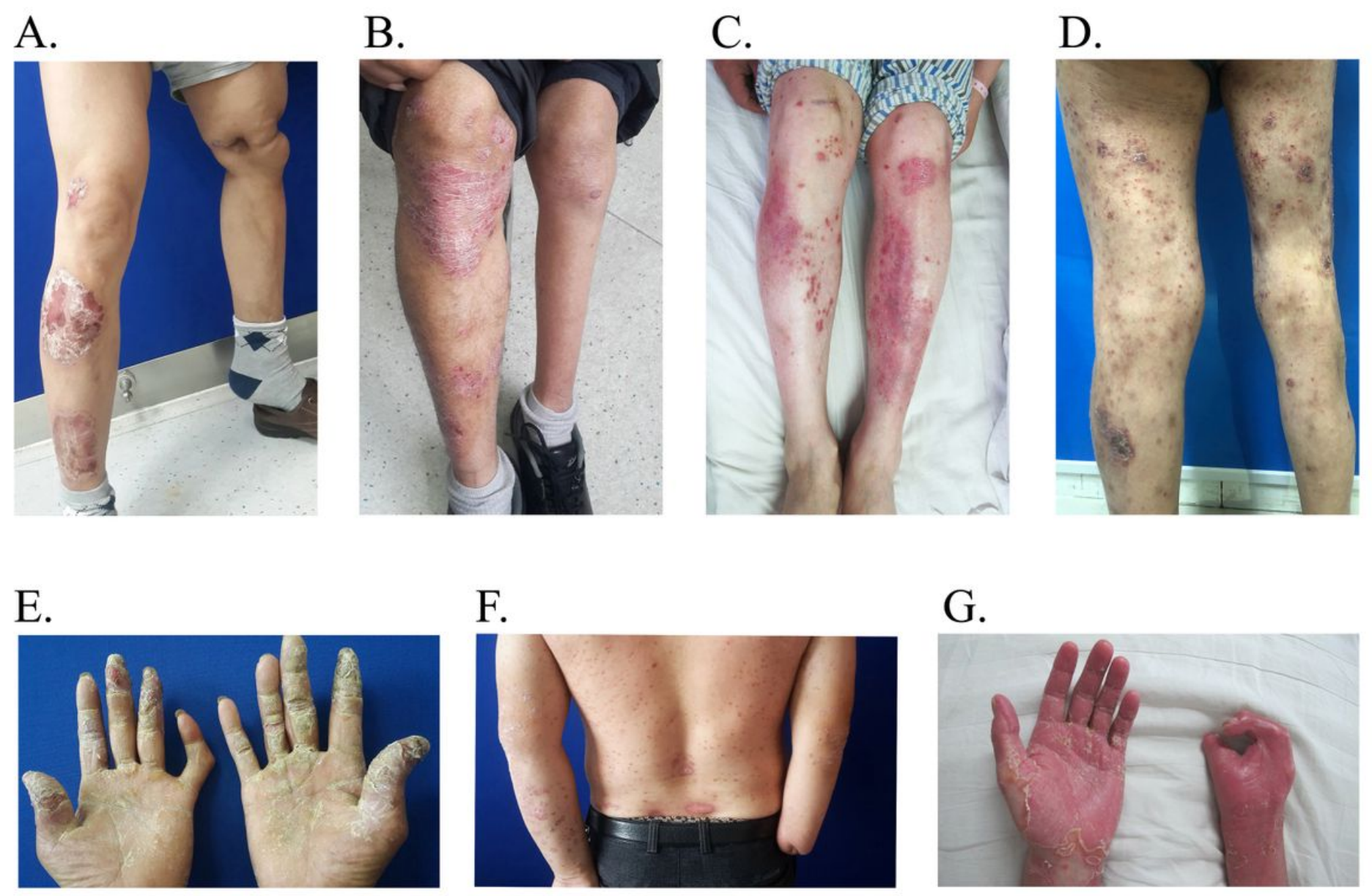

\section{Figure 1}

Cases of psoriatic patients in our clinical practice concomitantly suffered from the nerve injuries. A: Left knee injured by a car accident; B: Left lower limb suffered from poliomyelitis; C: Right knee injured by a trauma; D: Right lower limb suffered from poliomyelitis; E: Left little finger injured by a trauma; F: Right forearm suffered from an amputation; G: Right hand injured by a trauma. More details in Table 1. 
A.

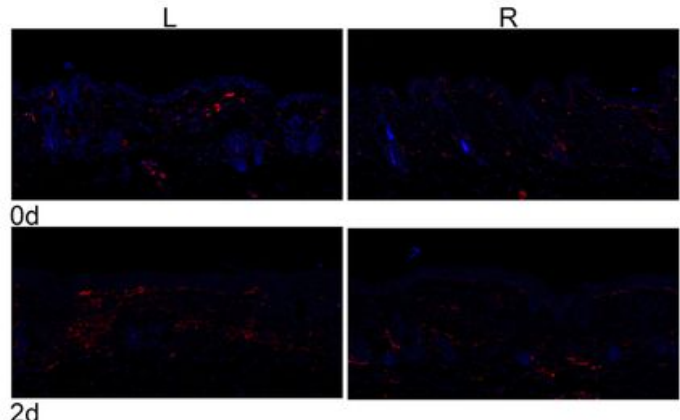

$2 \mathrm{~d}$

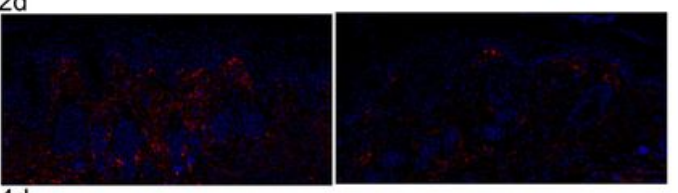

$4 d$

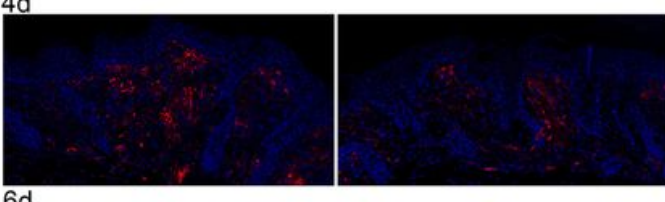

$6 d$
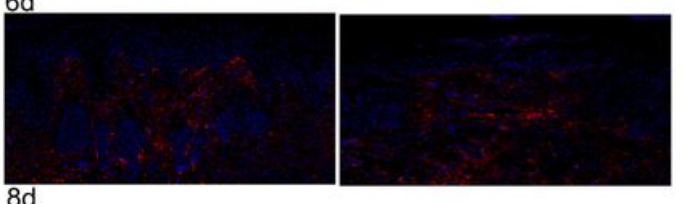

B.
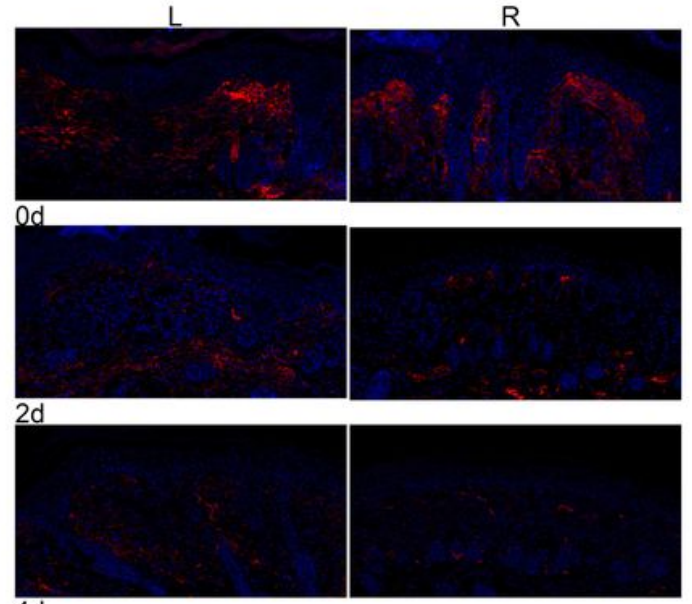

$4 d$

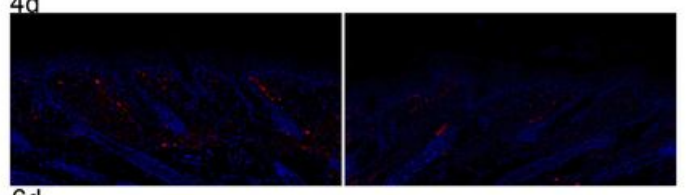

$6 d$

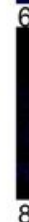

C.

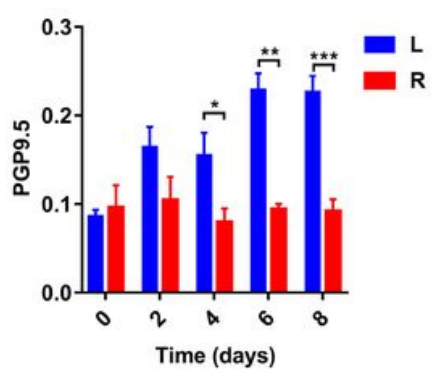

D.

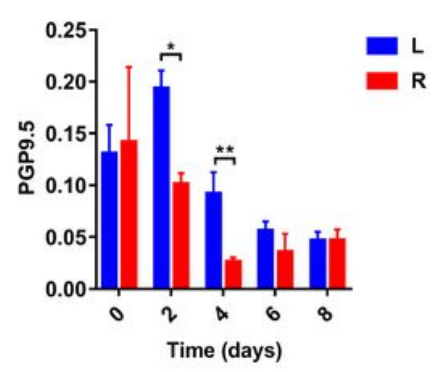

\section{Figure 2}

The consequence of unilateral denervation surgery shown by the immunofluorescence staining of PGP 9.5. A and C: The unilateral denervation was performed prior to the application of imiquimod. There are significantly increased nerves along with the induction of imiquimod on the normal side (Left) as compared with the denervation side (Right), *4th day, $\mathrm{t}=2.482, \mathrm{P}=0.038$; **6th day, $\mathrm{t}=8.457, \mathrm{P}<$ $0.001 ; * \star \star$ 8th day, $t=6.07, \mathrm{P}<0.001)$. $\mathrm{B}$ and $\mathrm{D}$ : The unilateral denervation was performed after the induction of psoriasiform dermatitis. The termination of imiquimod led the nerve gradually return to normal level, with strikingly less nerves on the denervation side (Right) than those on the normal side (Left), *2nd day, $t=6.797, \mathrm{P}<0.001 ; * \star 4$ th day, $\mathrm{t}=3.007, \mathrm{P}=0.017$ ). In panel A and $\mathrm{B}, \mathrm{Blue}$ : DAPI staining for cell nuclei; Red: PGP 9.5 staining for the nerves. 
A.

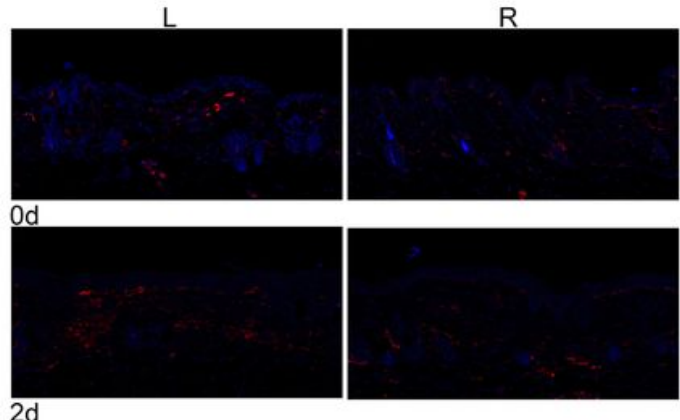

$2 \mathrm{~d}$

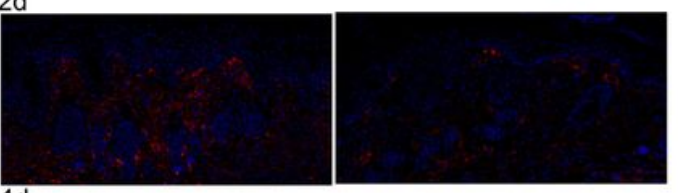

$4 d$

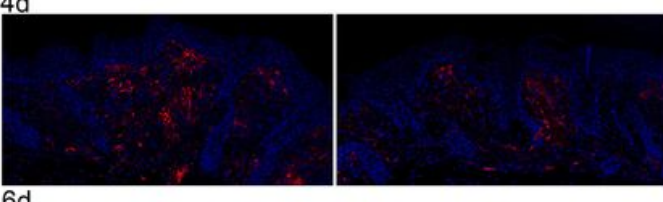

$6 d$
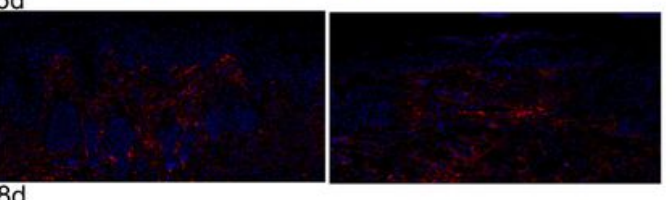

B.
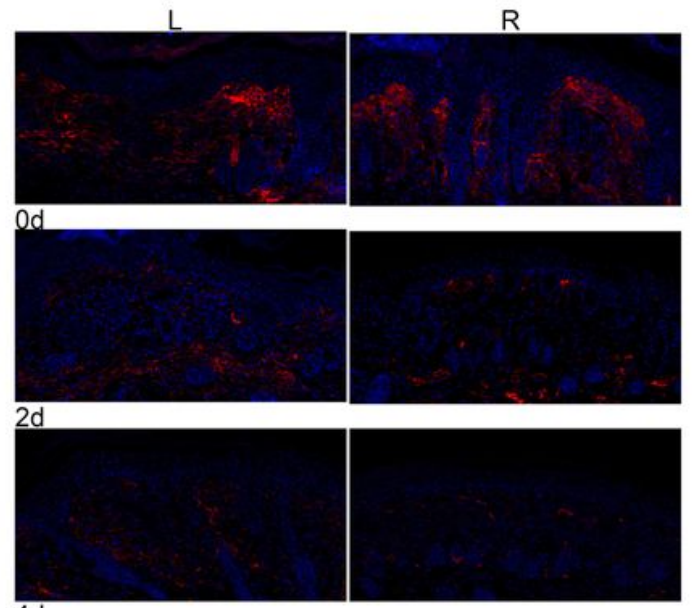

$4 d$

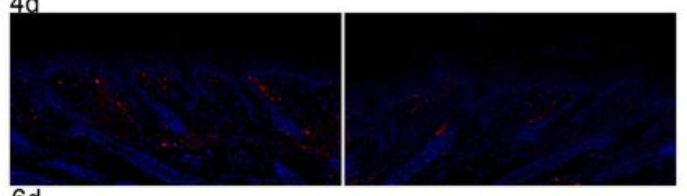

$6 d$

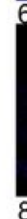

C.

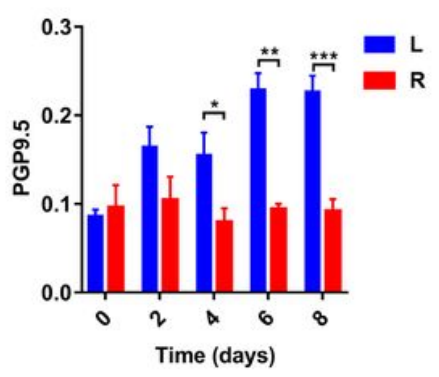

D.

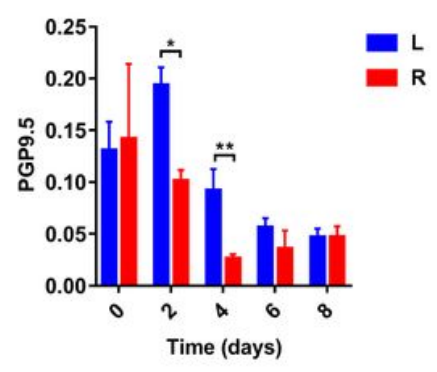

\section{Figure 2}

The consequence of unilateral denervation surgery shown by the immunofluorescence staining of PGP 9.5. A and C: The unilateral denervation was performed prior to the application of imiquimod. There are significantly increased nerves along with the induction of imiquimod on the normal side (Left) as compared with the denervation side (Right), *4th day, $\mathrm{t}=2.482, \mathrm{P}=0.038$; **6th day, $\mathrm{t}=8.457, \mathrm{P}<$ $0.001 ; * \star \star$ 8th day, $t=6.07, \mathrm{P}<0.001)$. $\mathrm{B}$ and $\mathrm{D}$ : The unilateral denervation was performed after the induction of psoriasiform dermatitis. The termination of imiquimod led the nerve gradually return to normal level, with strikingly less nerves on the denervation side (Right) than those on the normal side (Left), *2nd day, $t=6.797, \mathrm{P}<0.001 ; * \star 4$ th day, $\mathrm{t}=3.007, \mathrm{P}=0.017$ ). In panel A and $\mathrm{B}, \mathrm{Blue}$ : DAPI staining for cell nuclei; Red: PGP 9.5 staining for the nerves. 
A.

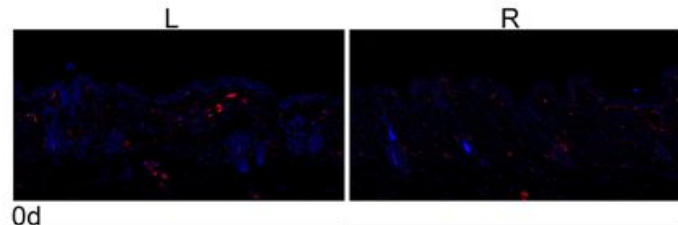

Od

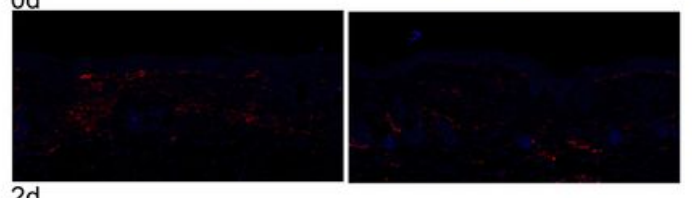

$2 \mathrm{~d}$

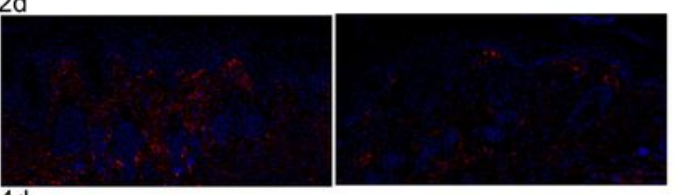

$4 d$

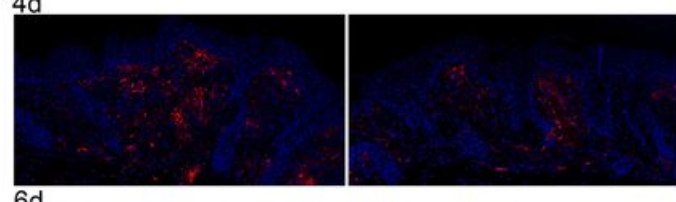

$6 \mathrm{~d}$
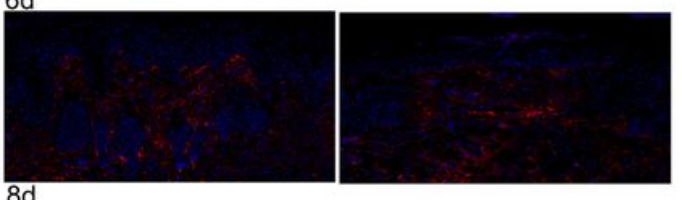

B.
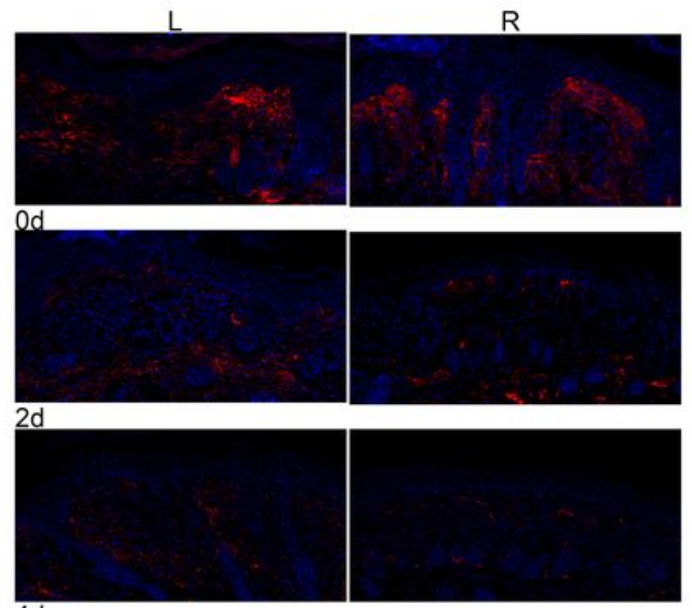

$4 d$

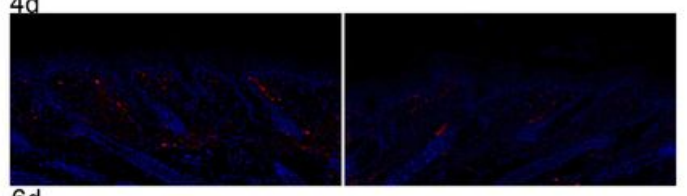

$6 d$

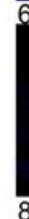

C.

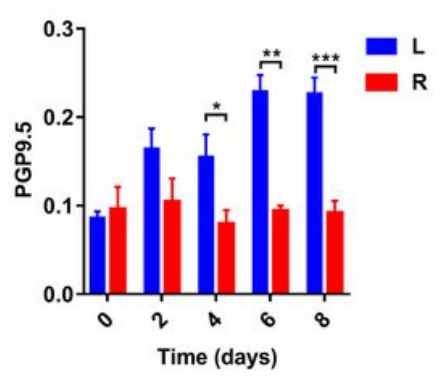

D.

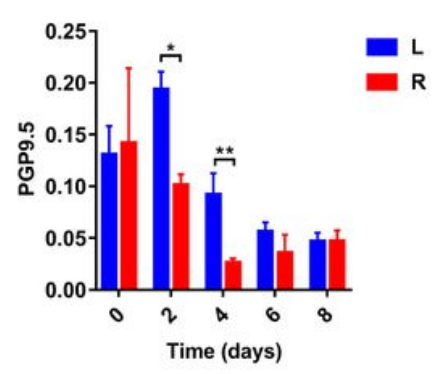

\section{Figure 2}

The consequence of unilateral denervation surgery shown by the immunofluorescence staining of PGP 9.5. A and C: The unilateral denervation was performed prior to the application of imiquimod. There are significantly increased nerves along with the induction of imiquimod on the normal side (Left) as compared with the denervation side (Right), *4th day, $\mathrm{t}=2.482, \mathrm{P}=0.038$; **6th day, $\mathrm{t}=8.457, \mathrm{P}<$ $0.001 ; * \star \star$ 8th day, $t=6.07, \mathrm{P}<0.001)$. $\mathrm{B}$ and $\mathrm{D}$ : The unilateral denervation was performed after the induction of psoriasiform dermatitis. The termination of imiquimod led the nerve gradually return to normal level, with strikingly less nerves on the denervation side (Right) than those on the normal side (Left), *2nd day, $t=6.797, \mathrm{P}<0.001 ; * \star 4$ th day, $\mathrm{t}=3.007, \mathrm{P}=0.017$ ). In panel A and $\mathrm{B}, \mathrm{Blue}$ : DAPI staining for cell nuclei; Red: PGP 9.5 staining for the nerves. 
A.

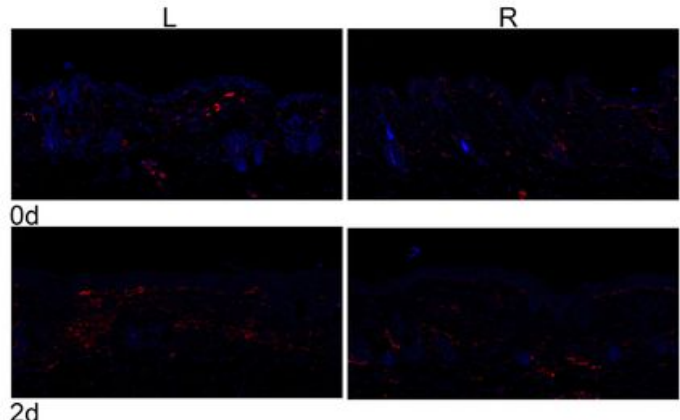

$2 \mathrm{~d}$

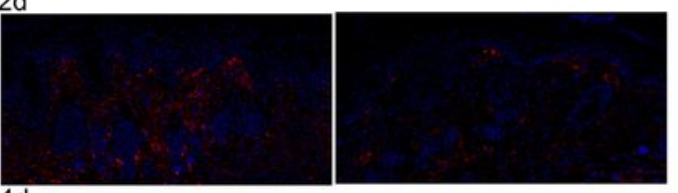

$4 d$

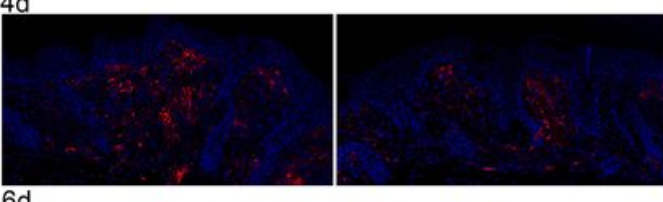

$6 d$
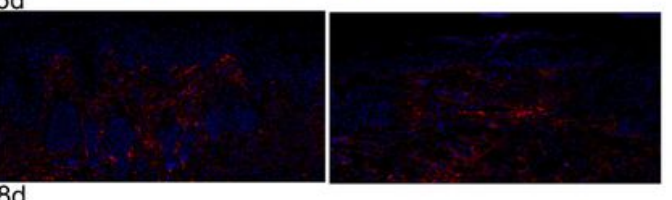

B.
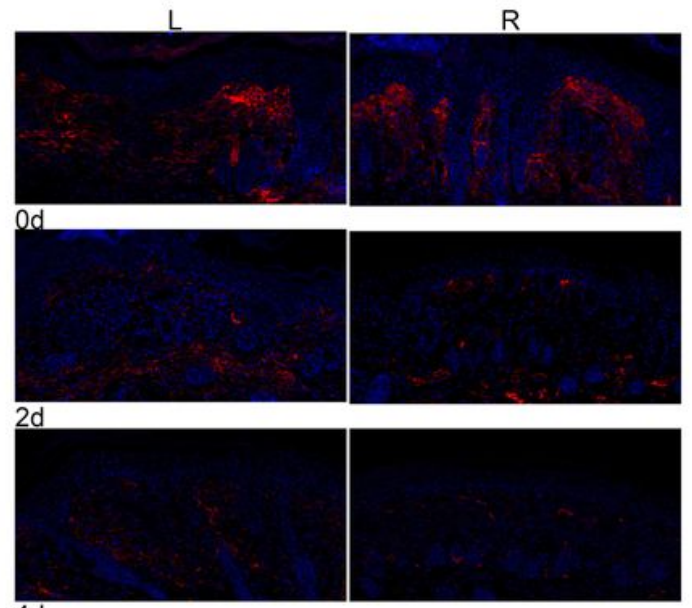

$4 d$

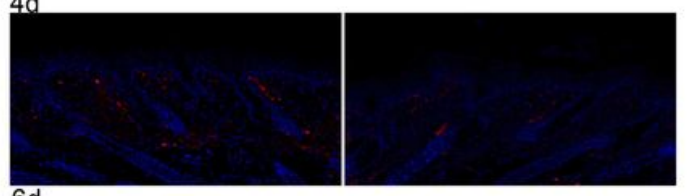

$6 d$

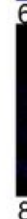

C.

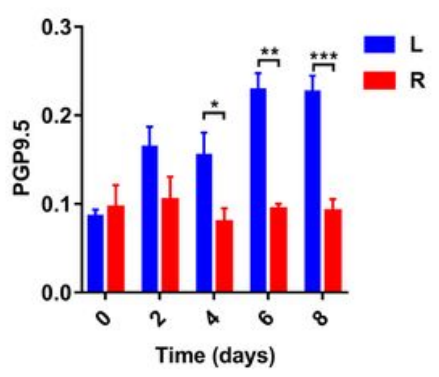

D.

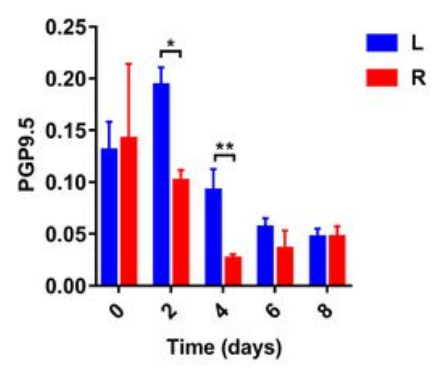

\section{Figure 2}

The consequence of unilateral denervation surgery shown by the immunofluorescence staining of PGP 9.5. A and C: The unilateral denervation was performed prior to the application of imiquimod. There are significantly increased nerves along with the induction of imiquimod on the normal side (Left) as compared with the denervation side (Right), *4th day, $\mathrm{t}=2.482, \mathrm{P}=0.038$; **6th day, $\mathrm{t}=8.457, \mathrm{P}<$ $0.001 ; * \star \star$ 8th day, $t=6.07, \mathrm{P}<0.001)$. $\mathrm{B}$ and $\mathrm{D}$ : The unilateral denervation was performed after the induction of psoriasiform dermatitis. The termination of imiquimod led the nerve gradually return to normal level, with strikingly less nerves on the denervation side (Right) than those on the normal side (Left), *2nd day, $t=6.797, \mathrm{P}<0.001 ; * \star 4$ th day, $\mathrm{t}=3.007, \mathrm{P}=0.017$ ). In panel A and $\mathrm{B}, \mathrm{Blue}$ : DAPI staining for cell nuclei; Red: PGP 9.5 staining for the nerves. 


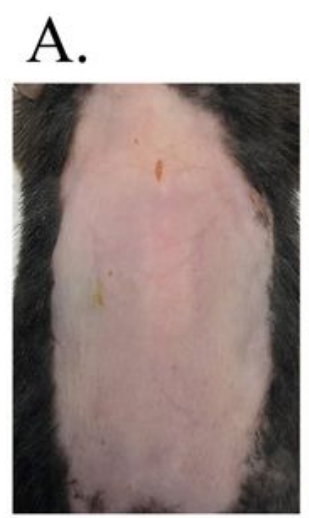

Od

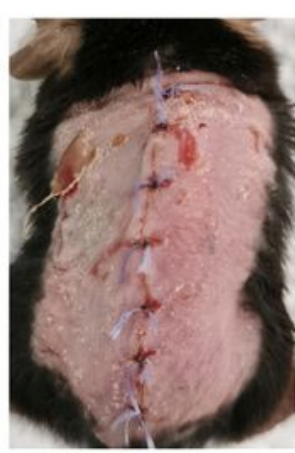

$2 d$

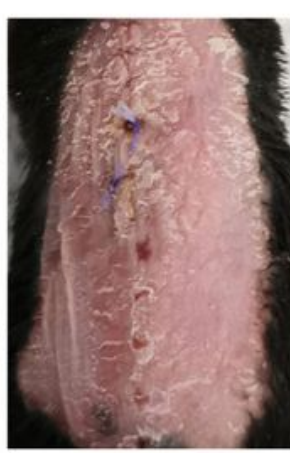

$4 d$

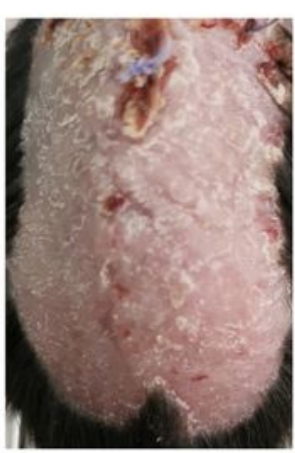

$6 d$

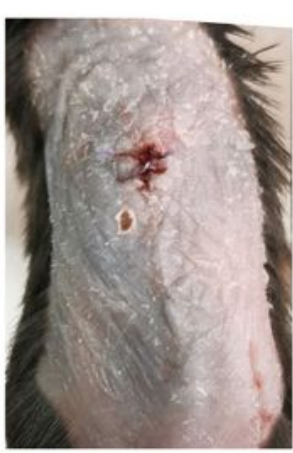

$8 d$
B.
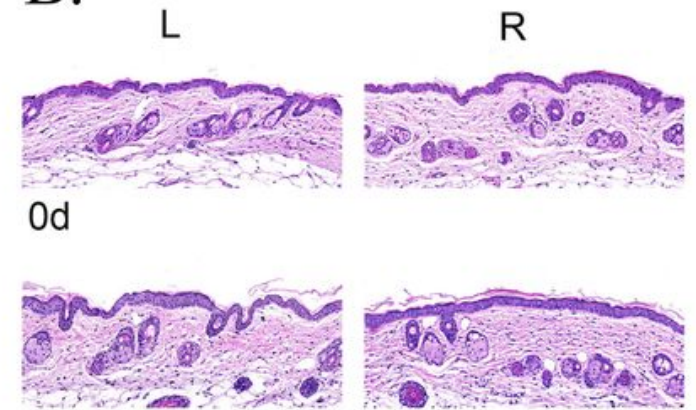

$2 d$
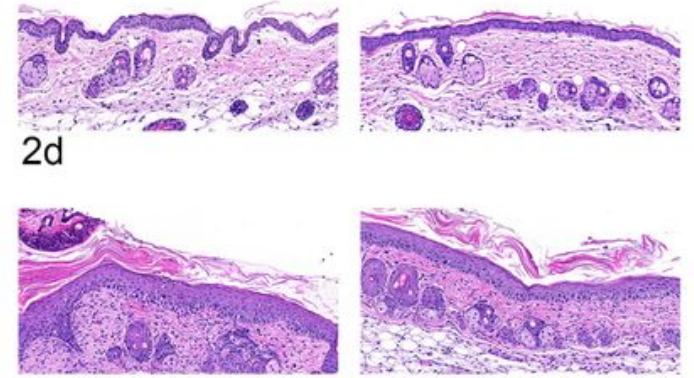

$4 d$

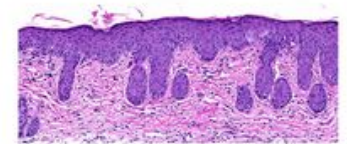

$6 d$

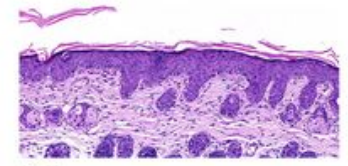

$8 d$
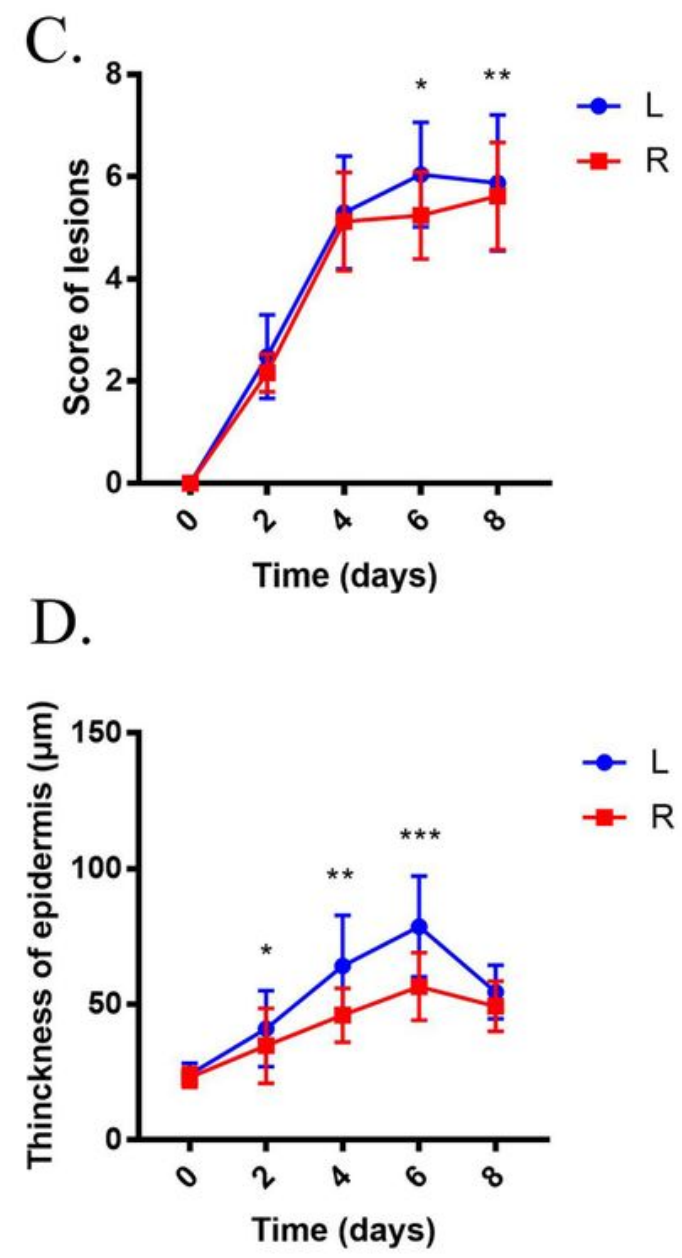

\section{Figure 3}

The unilateral denervation alleviated the severity of ipsilateral psoriasiform dermatitis induced by imiquimod. A: Changes of skin lesions on the normal side (Left) and the denervation side (Right) during the induction of imiquimod. B: Representative HE staining of imiquimod-induced psoriasiform dermatitis $(200 \mathrm{x})$. C: The analysis of the severity score of imiquimod-induced lesions $(n=20)$. Data were from panel A. *6th day, $t=5.181, P<0.001 ; * * 8$ th day, $t=2.072, P=0.044$. $D$ : The analysis of the epidermis 
thickness of imiquimod-induced lesions $(n=20)$. Data were from panel $B .{ }^{*} 2 n d$ day, $t=3.656, P=0.006$; $* * 4$ th day, $t=4.234, P=0.003 ; * \star * 6$ th day, $t=7.935, P<0.001$.

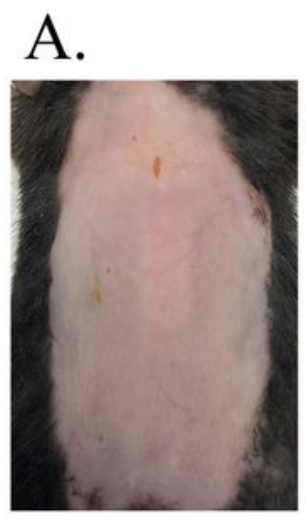

Od

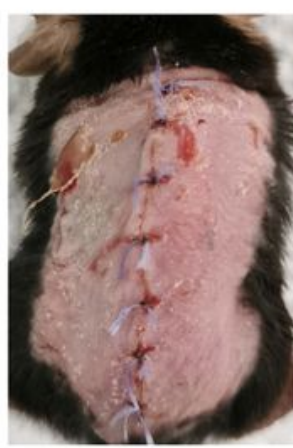

$2 \mathrm{~d}$

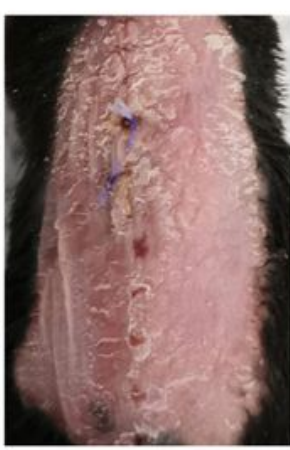

$4 d$

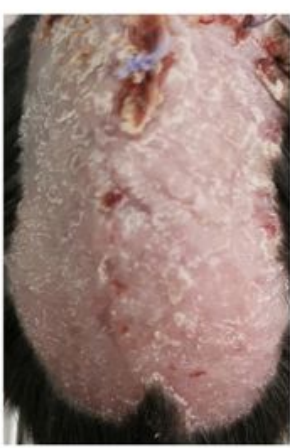

$6 d$

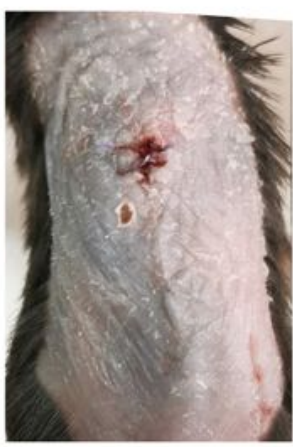

$8 d$
B.

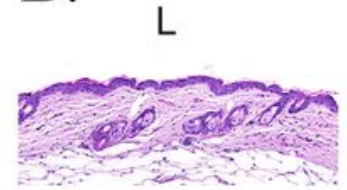

od

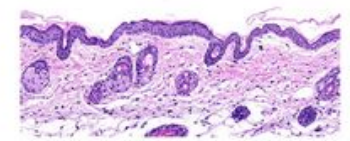

$2 d$

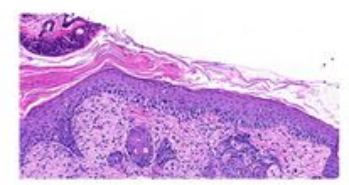

$4 d$

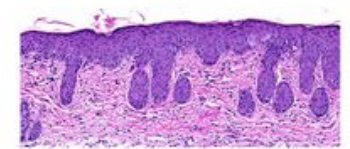

$6 d$

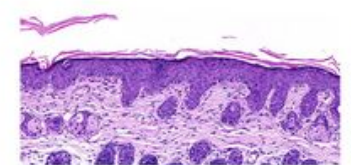

$8 d$
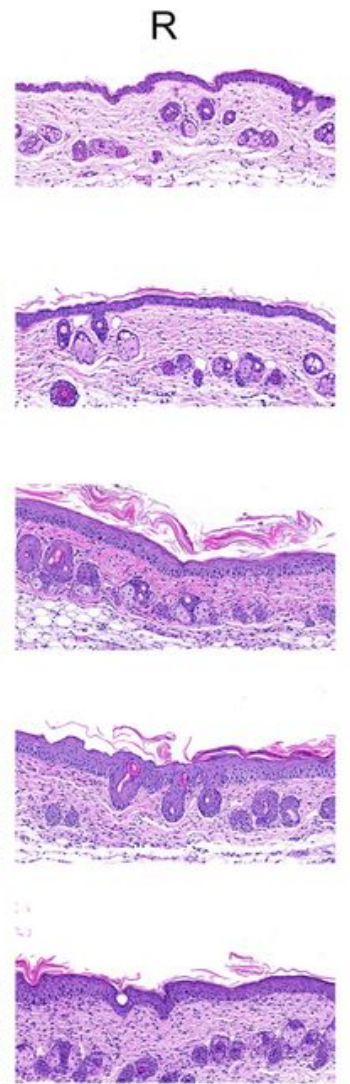

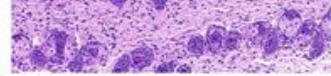
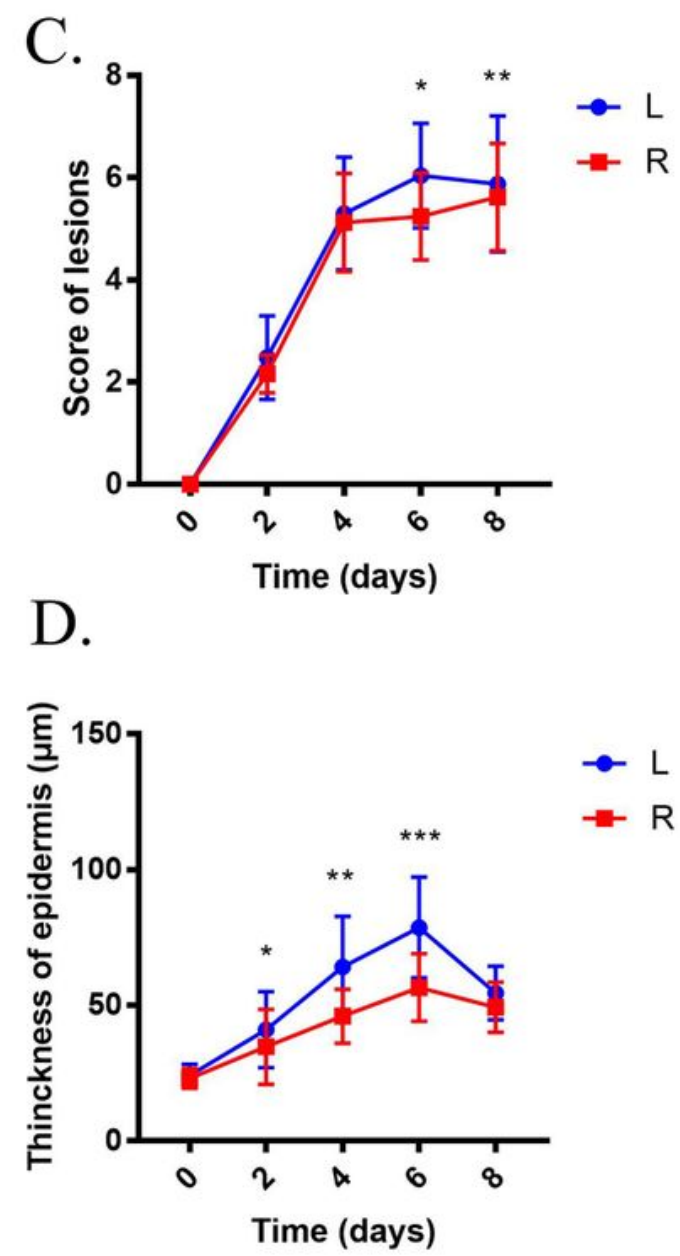

\section{Figure 3}

The unilateral denervation alleviated the severity of ipsilateral psoriasiform dermatitis induced by imiquimod. A: Changes of skin lesions on the normal side (Left) and the denervation side (Right) during the induction of imiquimod. B: Representative HE staining of imiquimod-induced psoriasiform dermatitis 
$(200 x)$. C: The analysis of the severity score of imiquimod-induced lesions $(n=20)$. Data were from panel A. *6th day, $t=5.181, P<0.001$; $* * 8$ th day, $t=2.072, P=0.044$. $D$ : The analysis of the epidermis thickness of imiquimod-induced lesions $(n=20)$. Data were from panel $B .{ }^{*} 2 n d$ day, $t=3.656, P=0.006$; $\star * 4$ th day, $t=4.234, \mathrm{P}=0.003 ; * \star * 6$ th day, $\mathrm{t}=7.935, \mathrm{P}<0.001$.

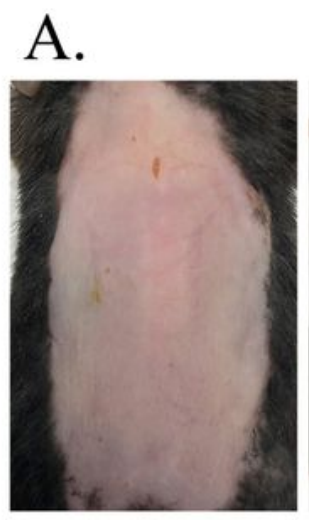

Od

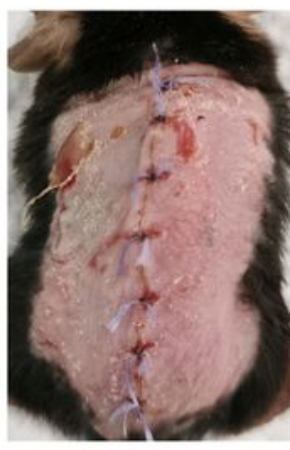

$2 d$

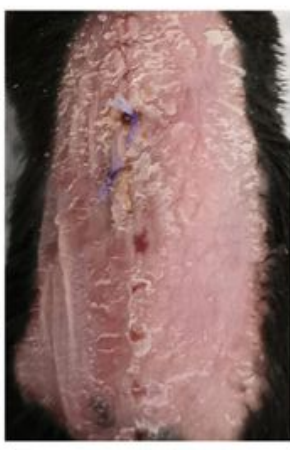

$4 d$

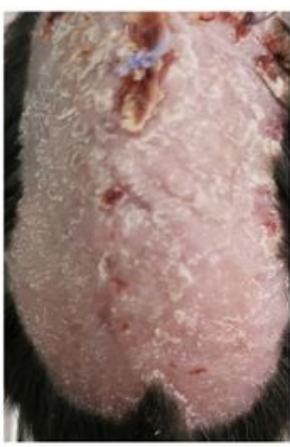

$6 d$

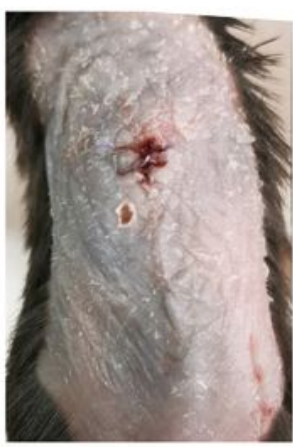

$8 d$
B.

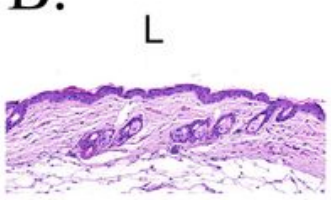

Od

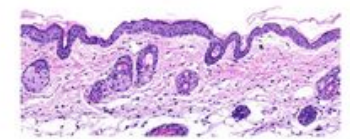

$2 d$

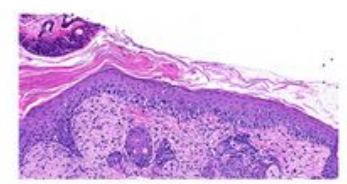

$4 d$

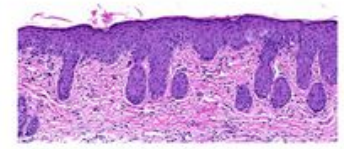

$6 d$

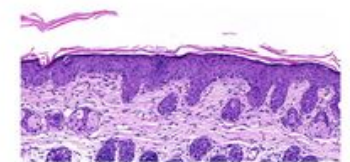

$8 d$
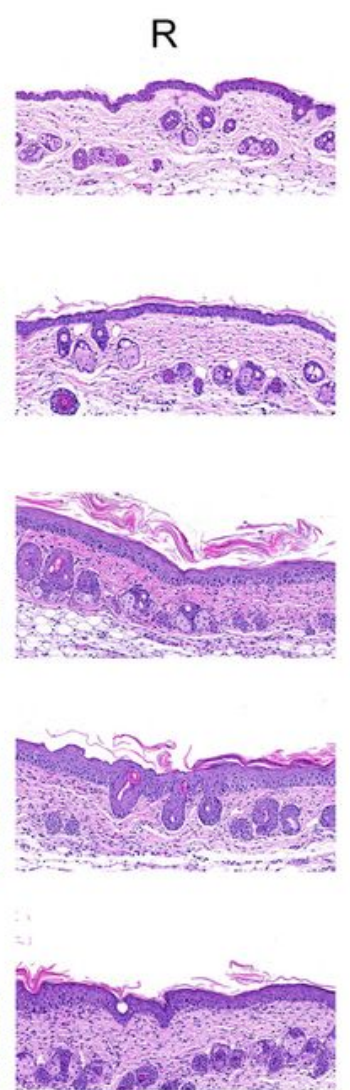

C.
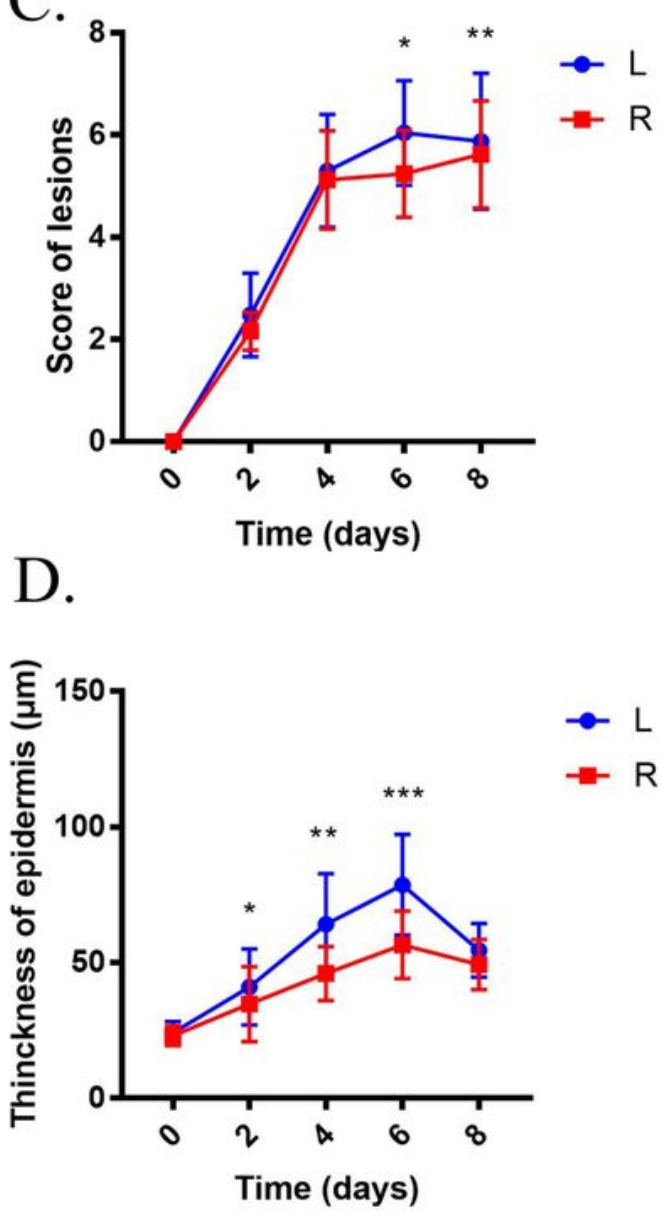

Figure 3 
The unilateral denervation alleviated the severity of ipsilateral psoriasiform dermatitis induced by imiquimod. A: Changes of skin lesions on the normal side (Left) and the denervation side (Right) during the induction of imiquimod. B: Representative HE staining of imiquimod-induced psoriasiform dermatitis $(200 x)$. C: The analysis of the severity score of imiquimod-induced lesions $(n=20)$. Data were from panel A. *6th day, $t=5.181, P<0.001 ; * \star 8$ th day, $t=2.072, P=0.044$. $D$ : The analysis of the epidermis thickness of imiquimod-induced lesions $(n=20)$. Data were from panel $B$. $* 2 n d$ day, $t=3.656, P=0.006$; $\star * 4$ th day, $t=4.234, P=0.003 ; * * * 6$ th day, $t=7.935, P<0.001$.

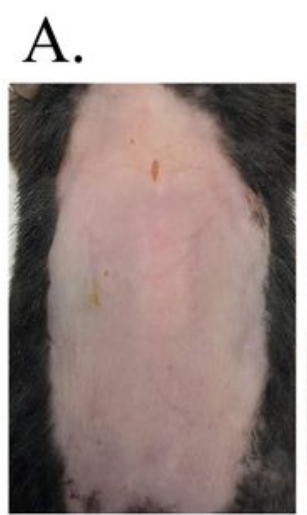

Od

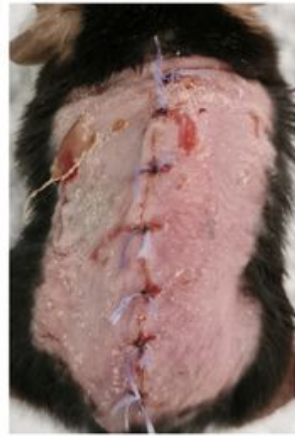

$2 \mathrm{~d}$

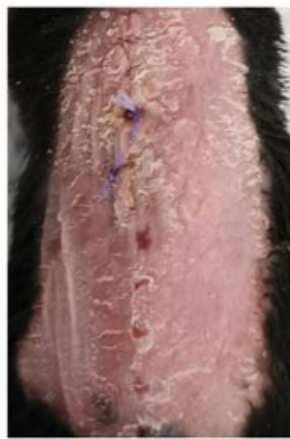

$4 d$

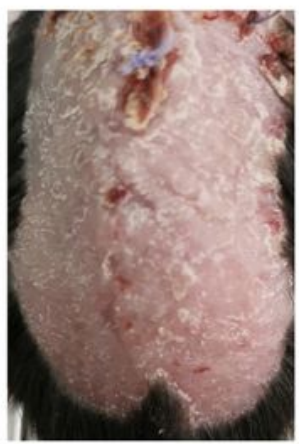

$6 d$

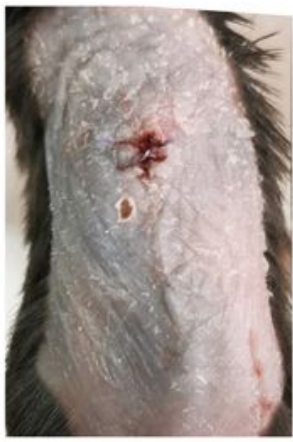

$8 d$
B.

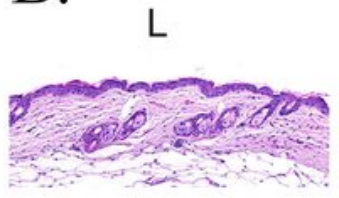

Od

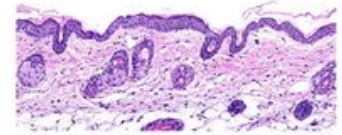

$2 d$

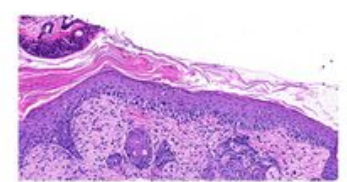

$4 d$

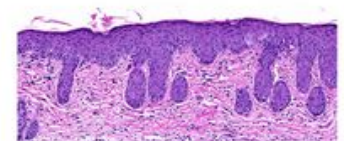

$6 d$

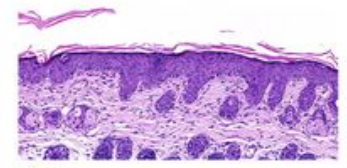

$8 d$
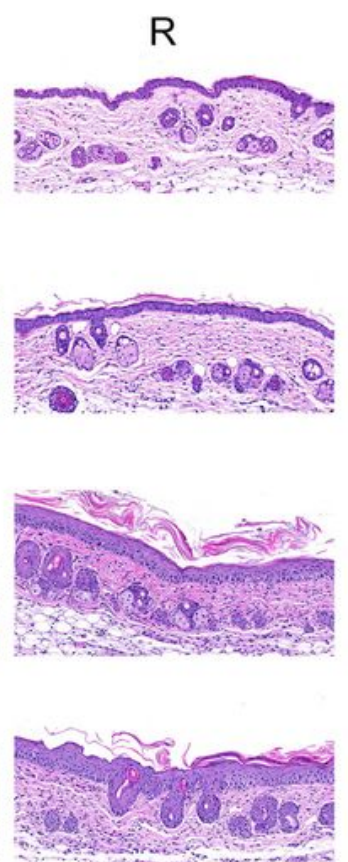

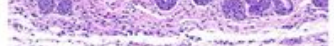

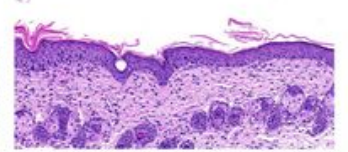

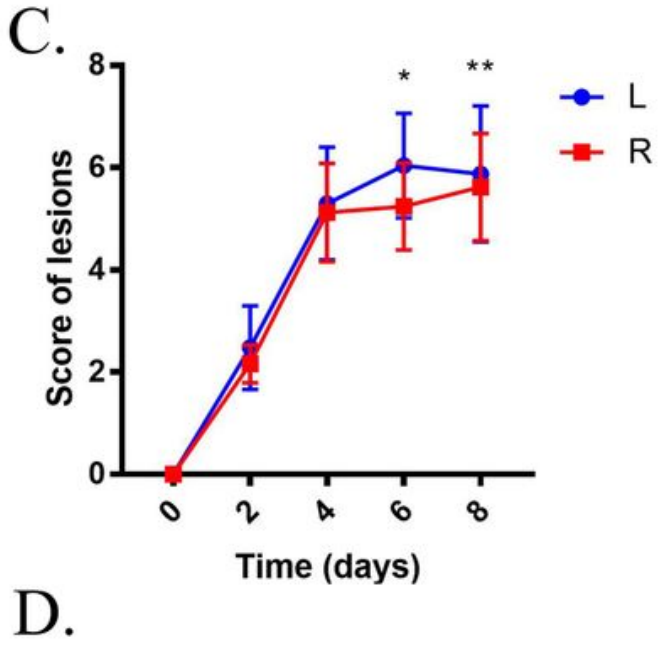

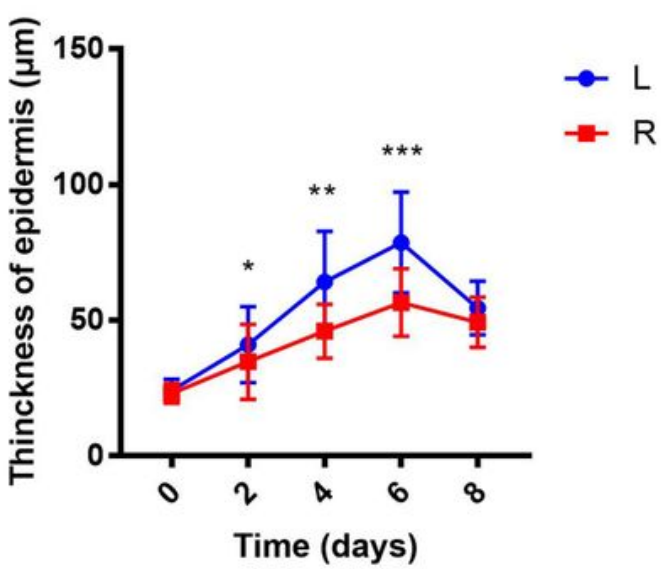




\section{Figure 3}

The unilateral denervation alleviated the severity of ipsilateral psoriasiform dermatitis induced by imiquimod. A: Changes of skin lesions on the normal side (Left) and the denervation side (Right) during the induction of imiquimod. B: Representative HE staining of imiquimod-induced psoriasiform dermatitis $(200 x)$. C: The analysis of the severity score of imiquimod-induced lesions $(n=20)$. Data were from panel A. *6th day, $t=5.181, P<0.001$; $* * 8$ th day, $t=2.072, P=0.044$. $D$ : The analysis of the epidermis thickness of imiquimod-induced lesions $(n=20)$. Data were from panel $B .{ }^{*} 2 n d$ day, $t=3.656, P=0.006$; $\star \star 4$ th day, $t=4.234, P=0.003 ; * \star * 6$ th day, $t=7.935, P<0.001$. 


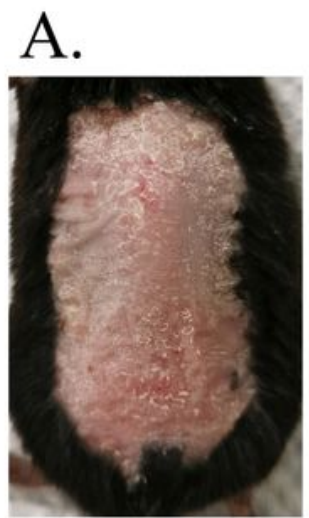

Od

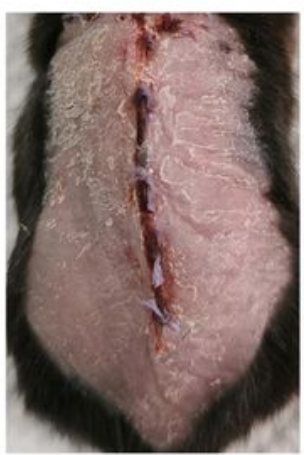

$2 d$

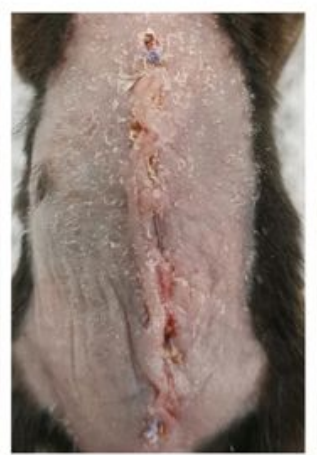

$4 d$

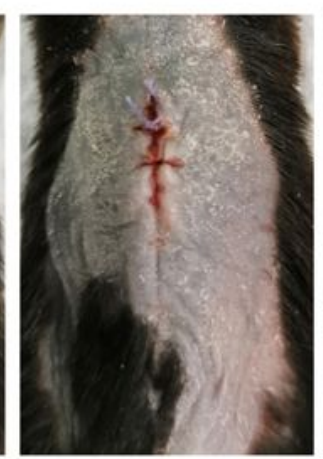

$6 d$

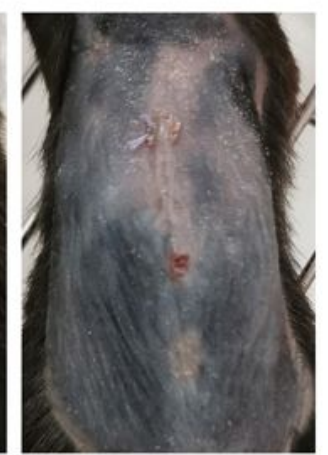

$8 d$
B.

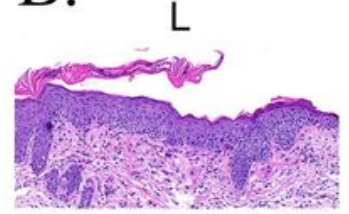

Od

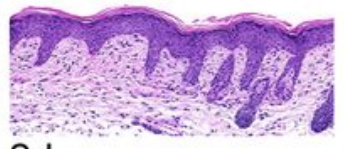

$2 d$

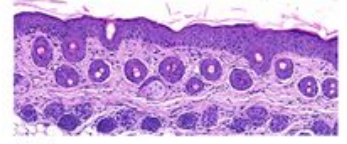
$4 d$

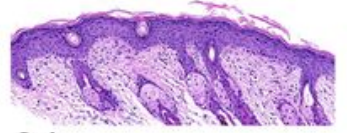

$6 d$
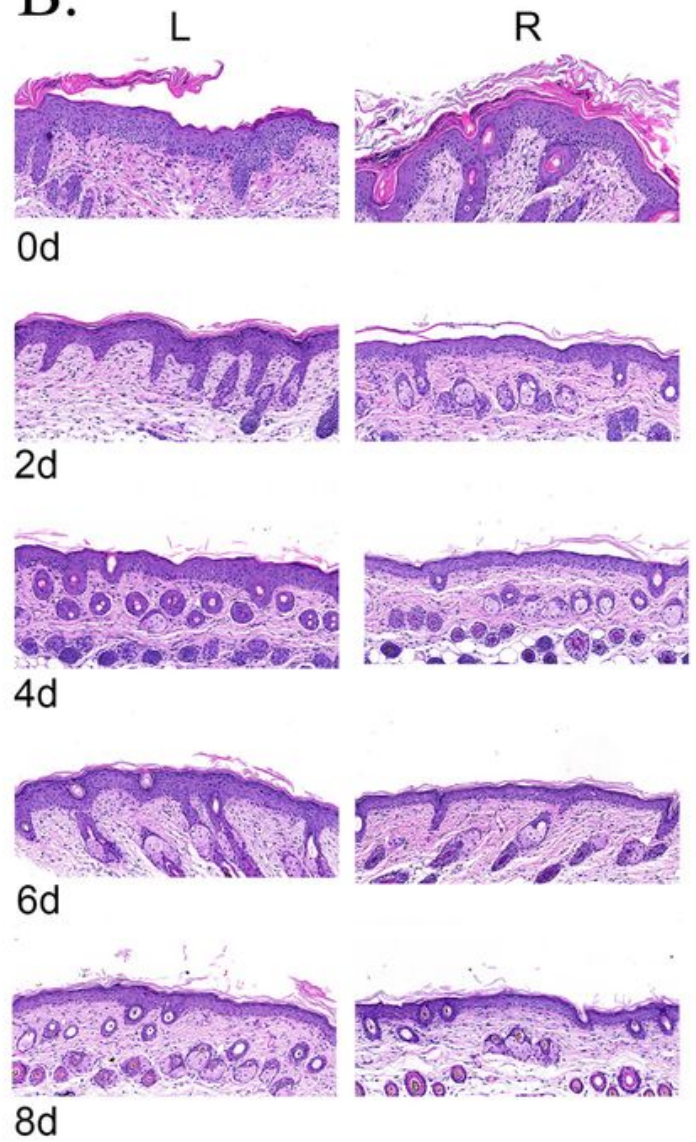
- 000 $00 \%$.

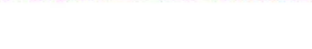

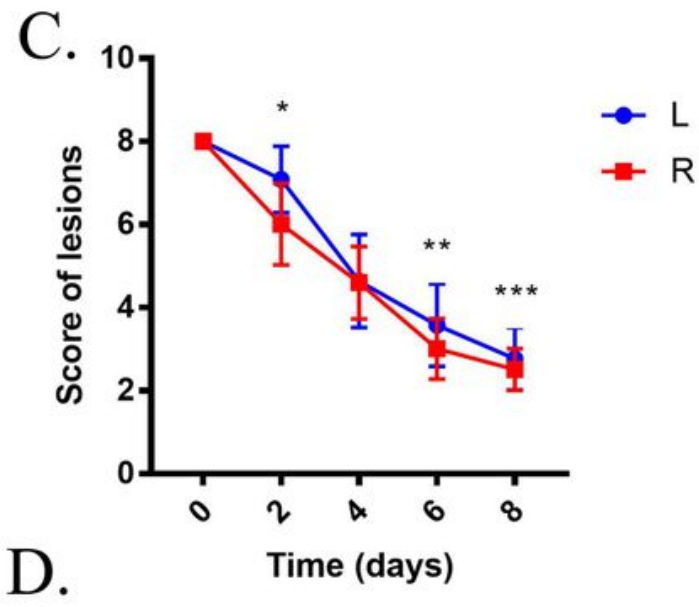

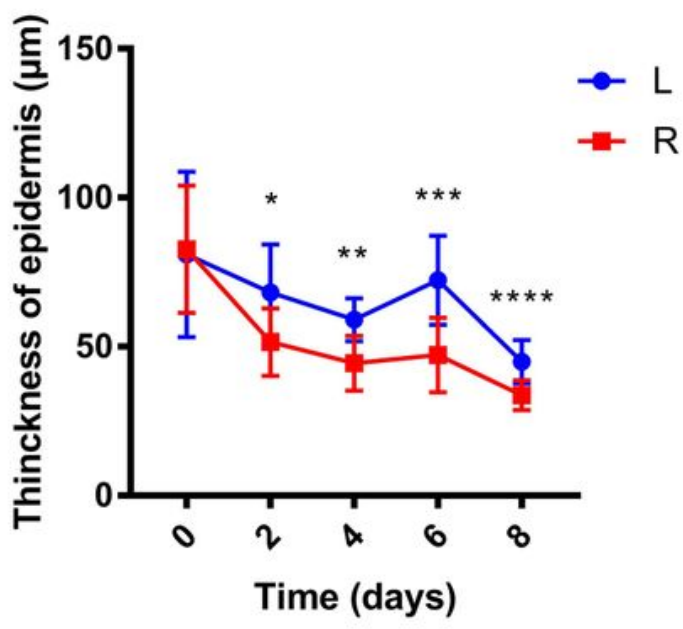

\section{Figure 4}

The unilateral denervation promoted the recovery of ipsilateral psoriasiform dermatitis. A: Changes of skin lesions on the normal side (Left) and the denervation side (Right) after the termination of imiquimod. B: Representative HE staining of the recovery of psoriasiform dermatitis $(200 \mathrm{x})$. C: The analysis of the recovery of imiquimod-induced lesions by scores $(n=20)$. Data were from panel $A$. $* 2 n d$ day, $t=10.35, P$ $<0.001 ; * * 6$ th day, $t=7.75, P<0.001 ; * * * 8 t h$ day, $t=2.563, P=0.017$. $D$ : The analysis of the epidermis 
thickness of imiquimod-induced lesions $(n=20)$. Data were from panel $B$. *2nd day, $t=5.529, P=0.001$; $\star * 4$ th day, $t=7.807, \mathrm{P}<0.001 ; * * * 6$ th day, $\mathrm{t}=7.086, \mathrm{P}<0.001 ; * \star * * 8$ th day, $\mathrm{t}=9.205, \mathrm{P}<0.001$.

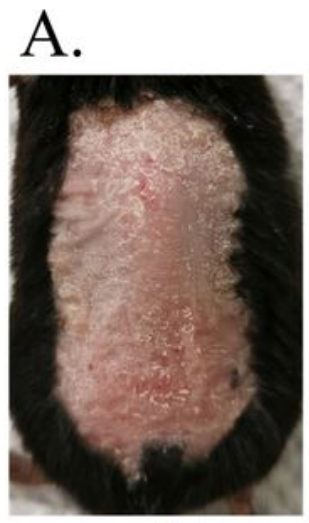

Od

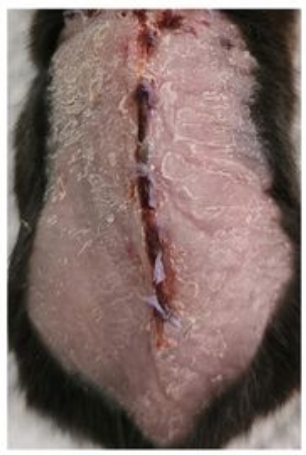

$2 d$

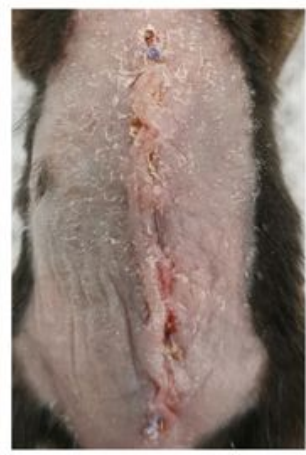

$4 d$

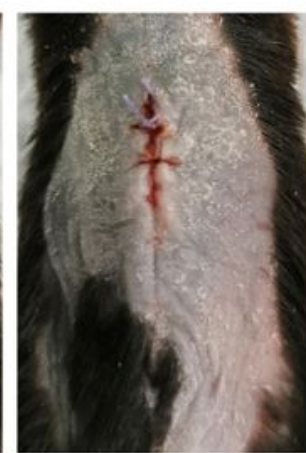

$6 d$

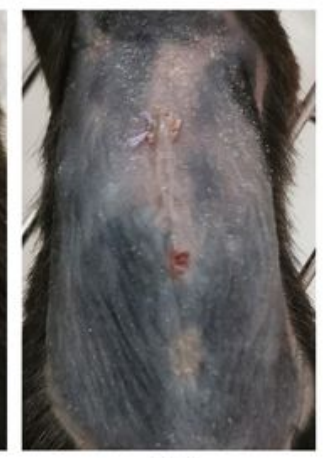

$8 d$
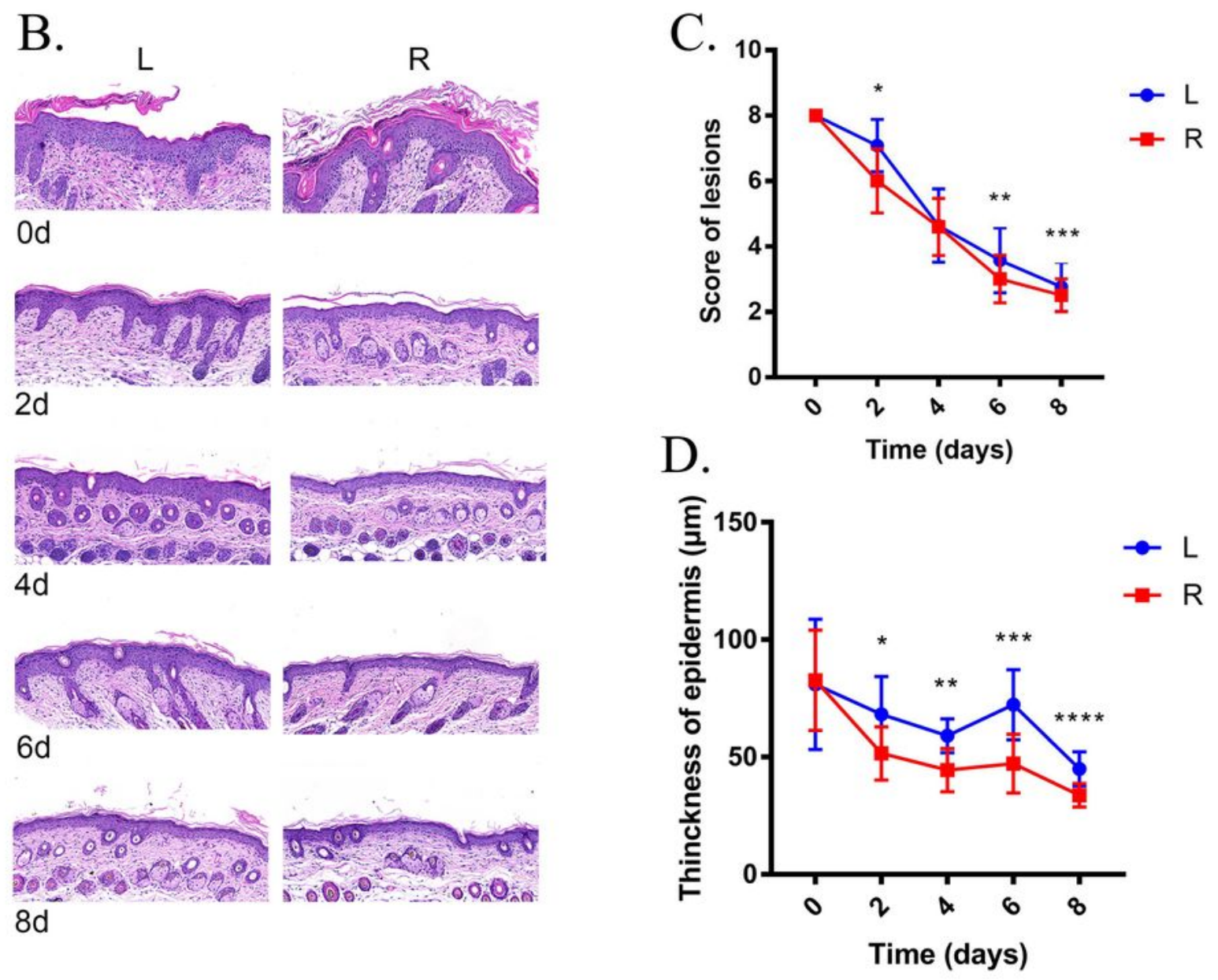

Figure 4

The unilateral denervation promoted the recovery of ipsilateral psoriasiform dermatitis. A: Changes of skin lesions on the normal side (Left) and the denervation side (Right) after the termination of imiquimod. $\mathrm{B}$ : Representative HE staining of the recovery of psoriasiform dermatitis $(200 \mathrm{x})$. C: The analysis of the 
recovery of imiquimod-induced lesions by scores $(n=20)$. Data were from panel $A$. *2nd day, $t=10.35, P$ $<0.001$; **6th day, $t=7.75, P<0.001 ; * \star * 8$ th day, $t=2.563, P=0.017$. $D$ : The analysis of the epidermis thickness of imiquimod-induced lesions $(n=20)$. Data were from panel $B . * 2 n d$ day, $t=5.529, P=0.001$; $* * 4$ th day, $t=7.807, \mathrm{P}<0.001 ; * * * 6$ th day, $\mathrm{t}=7.086, \mathrm{P}<0.001 ; * * * * 8$ th day, $\mathrm{t}=9.205, \mathrm{P}<0.001$.

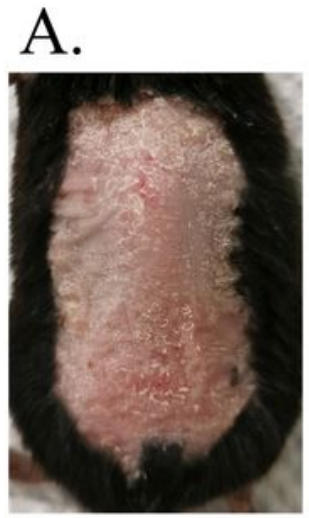

Od

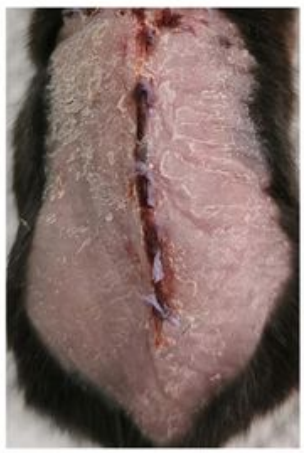

$2 \mathrm{~d}$

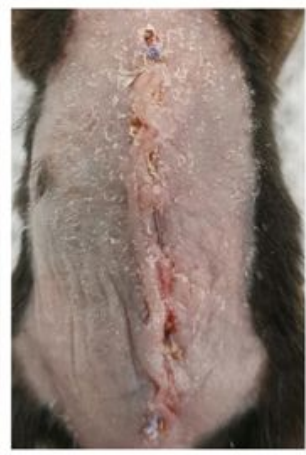

$4 d$

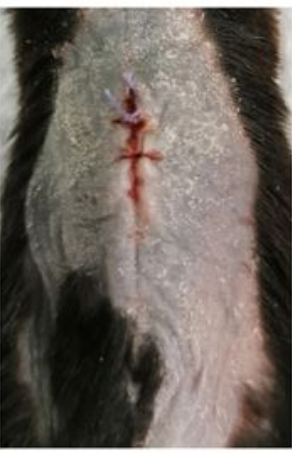

$6 d$

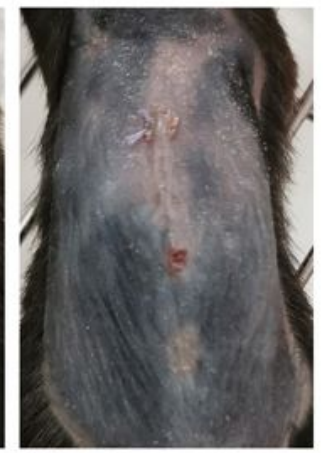

$8 d$
B.

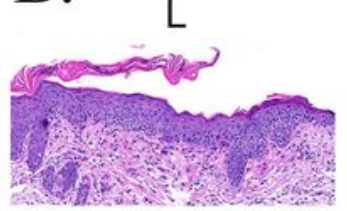

Od
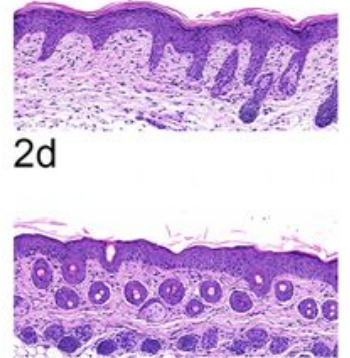

$4 d$

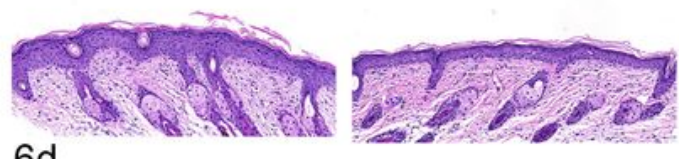

$6 d$

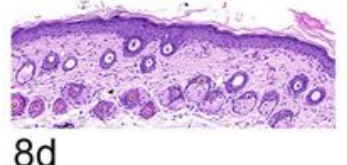

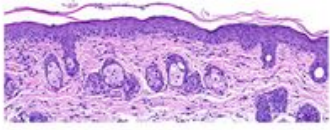
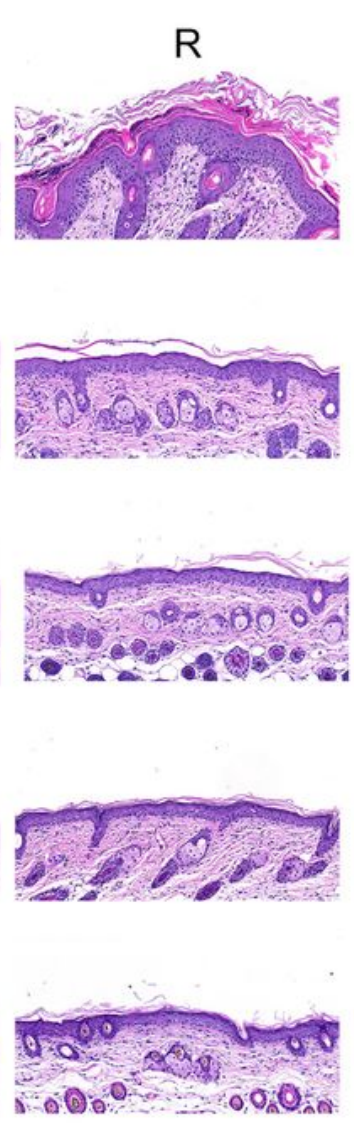

(1)
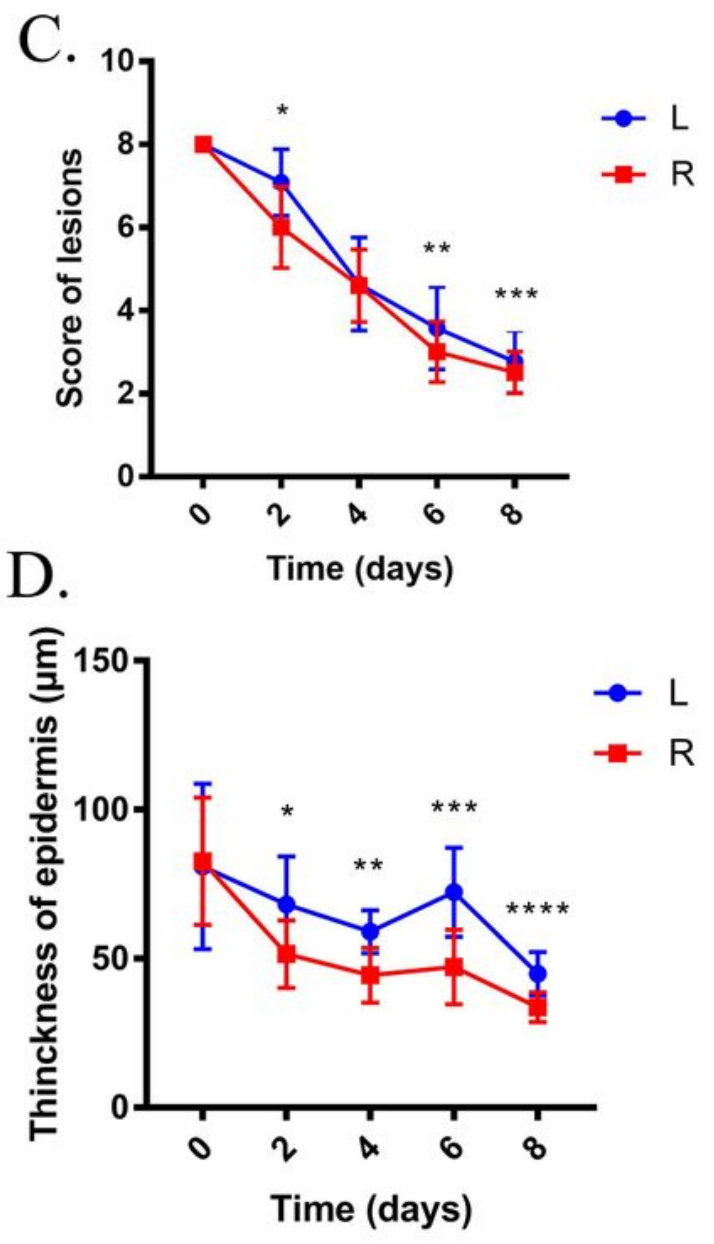

Figure 4 
The unilateral denervation promoted the recovery of ipsilateral psoriasiform dermatitis. A: Changes of skin lesions on the normal side (Left) and the denervation side (Right) after the termination of imiquimod. $\mathrm{B}$ : Representative HE staining of the recovery of psoriasiform dermatitis $(200 \mathrm{x})$. C: The analysis of the recovery of imiquimod-induced lesions by scores $(n=20)$. Data were from panel $A$. *2nd day, $t=10.35, P$ $<0.001 ; * * 6$ th day, $t=7.75, P<0.001 ; * * * 8$ th day, $t=2.563, P=0.017$. $D$ : The analysis of the epidermis thickness of imiquimod-induced lesions $(n=20)$. Data were from panel $B . * 2 n d$ day, $t=5.529, P=0.001$; $* * 4$ th day, $t=7.807, \mathrm{P}<0.001 ; * * * 6$ th day, $\mathrm{t}=7.086, \mathrm{P}<0.001 ; * * * * 8$ th day, $\mathrm{t}=9.205, \mathrm{P}<0.001$.

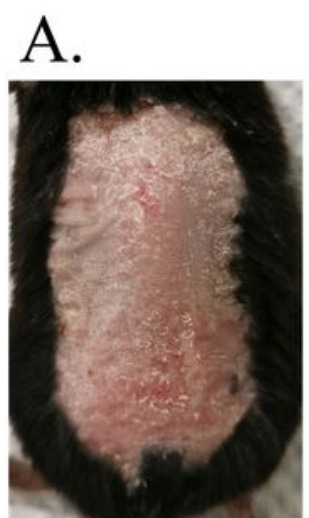

Od

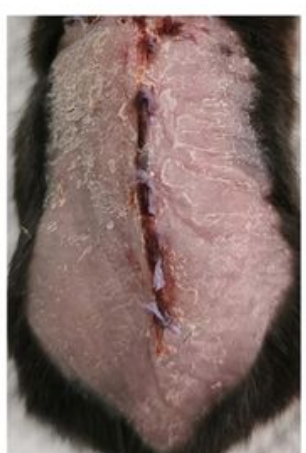

$2 \mathrm{~d}$

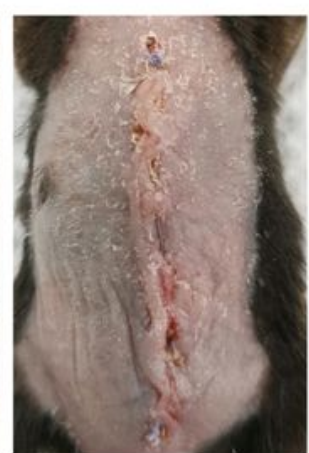

$4 d$

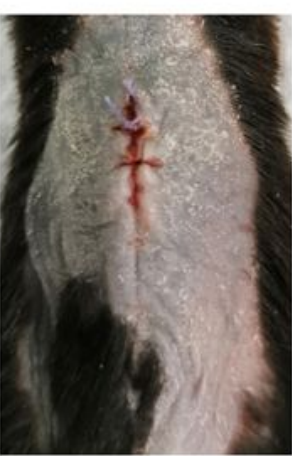

$6 d$

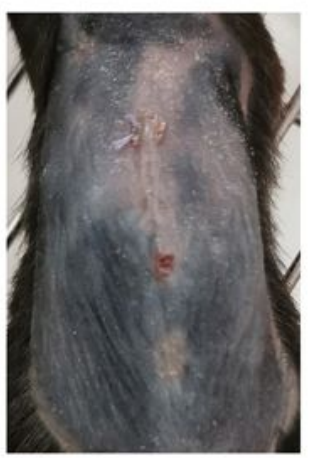

$8 d$
B.

L

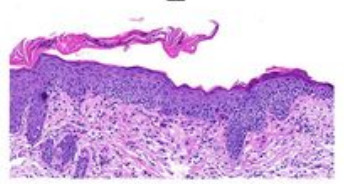

Od

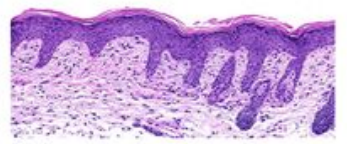

$2 d$

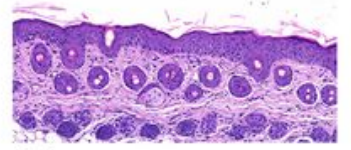
$4 d$

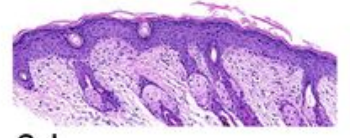

$6 d$
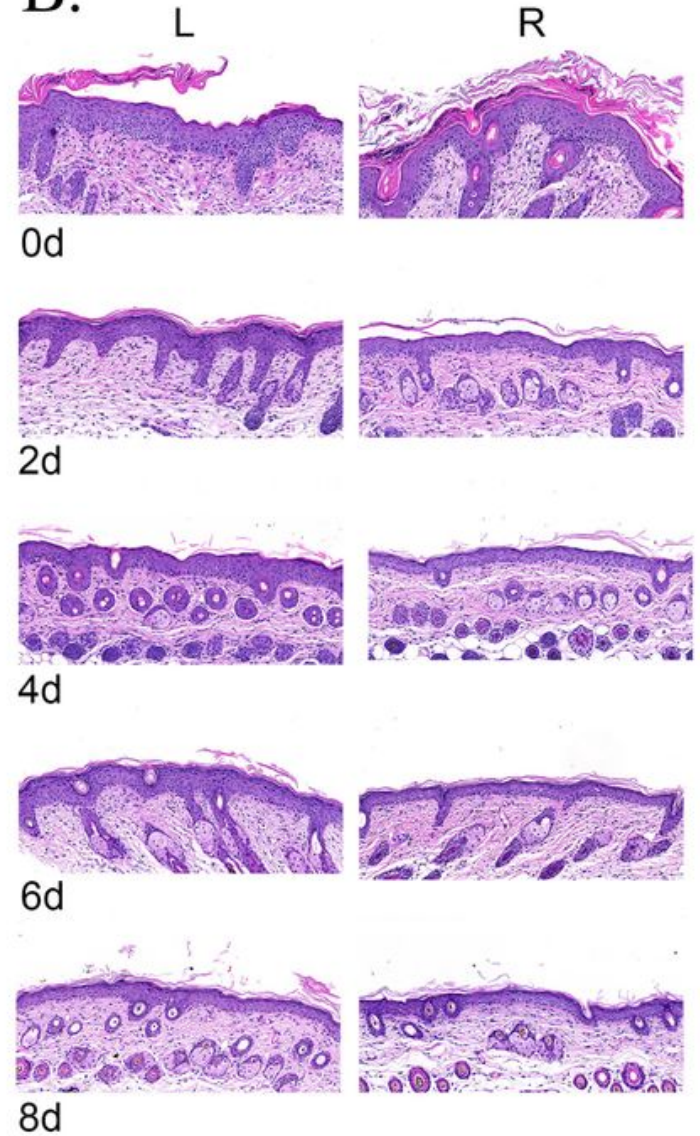
$100.0-0,00$. $8 d$
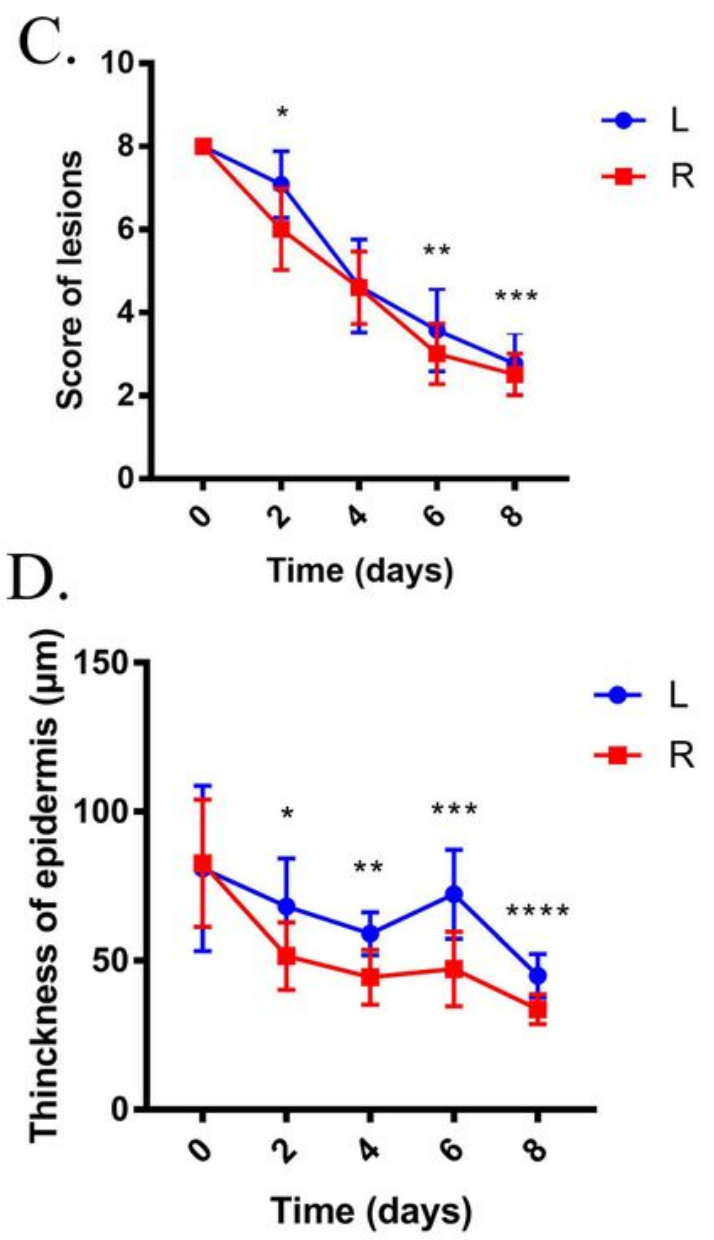


\section{Figure 4}

The unilateral denervation promoted the recovery of ipsilateral psoriasiform dermatitis. A: Changes of skin lesions on the normal side (Left) and the denervation side (Right) after the termination of imiquimod. $\mathrm{B}$ : Representative HE staining of the recovery of psoriasiform dermatitis $(200 \mathrm{x})$. C: The analysis of the recovery of imiquimod-induced lesions by scores $(n=20)$. Data were from panel $A$. ${ }^{*} 2 n d$ day, $t=10.35, P$ $<0.001$; **6th day, $t=7.75, P<0.001 ; * \star \star 8$ th day, $t=2.563, P=0.017$. $D$ : The analysis of the epidermis thickness of imiquimod-induced lesions $(n=20)$. Data were from panel $B$. *2nd day, $t=5.529, P=0.001$; $\star * 4$ th day, $t=7.807, \mathrm{P}<0.001 ; * * * 6$ th day, $\mathrm{t}=7.086, \mathrm{P}<0.001 ; * * \star * 8$ th day, $\mathrm{t}=9.205, \mathrm{P}<0.001$.

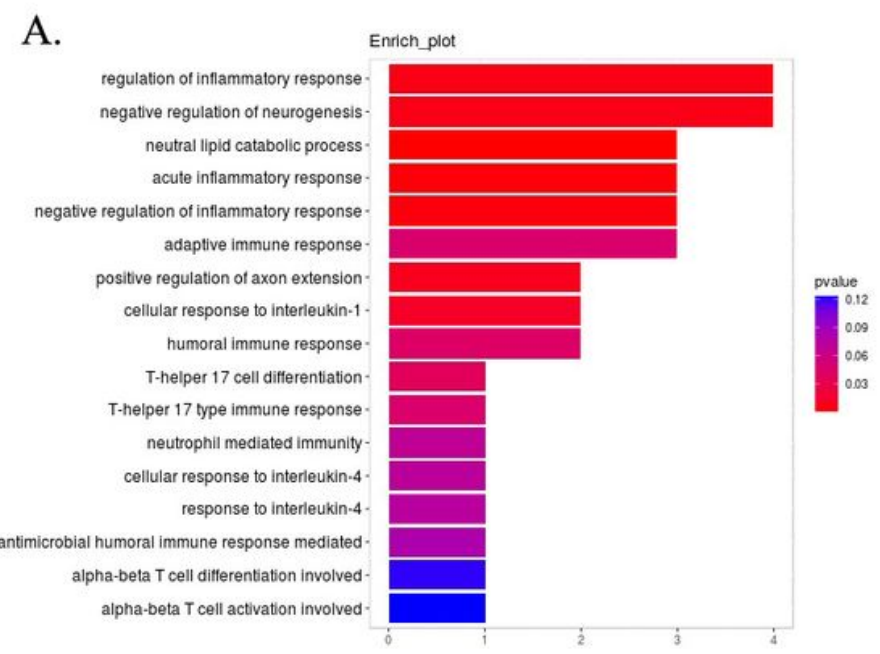

C.

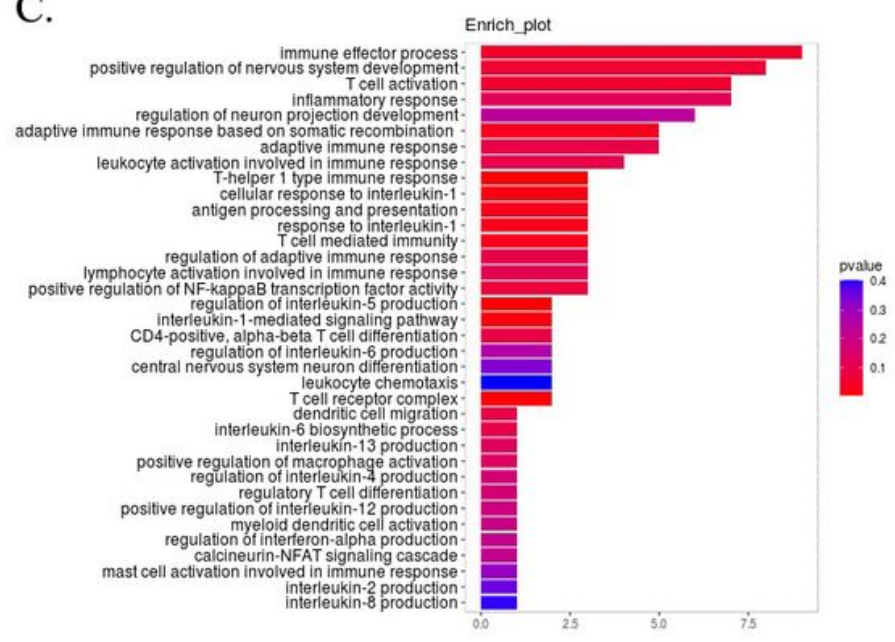

B.

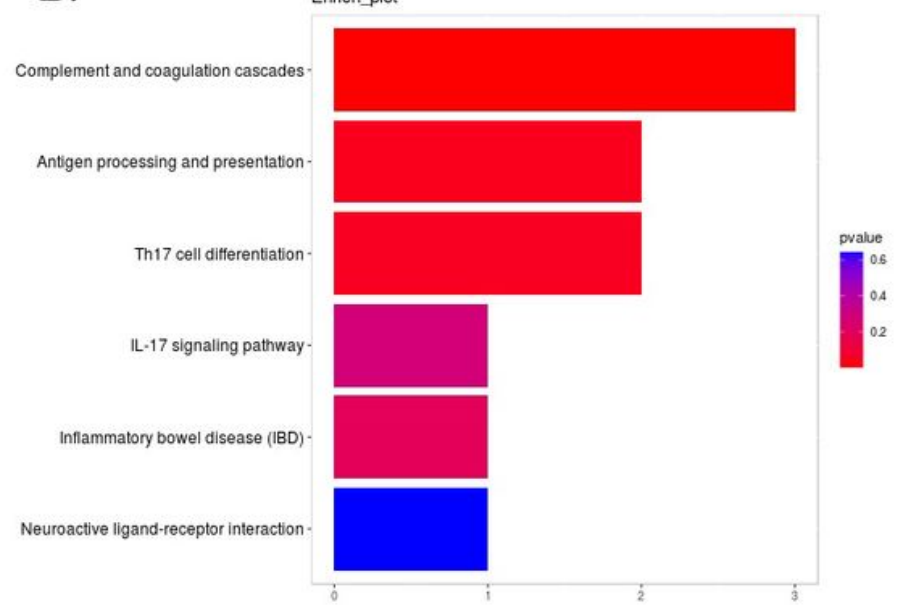

D.

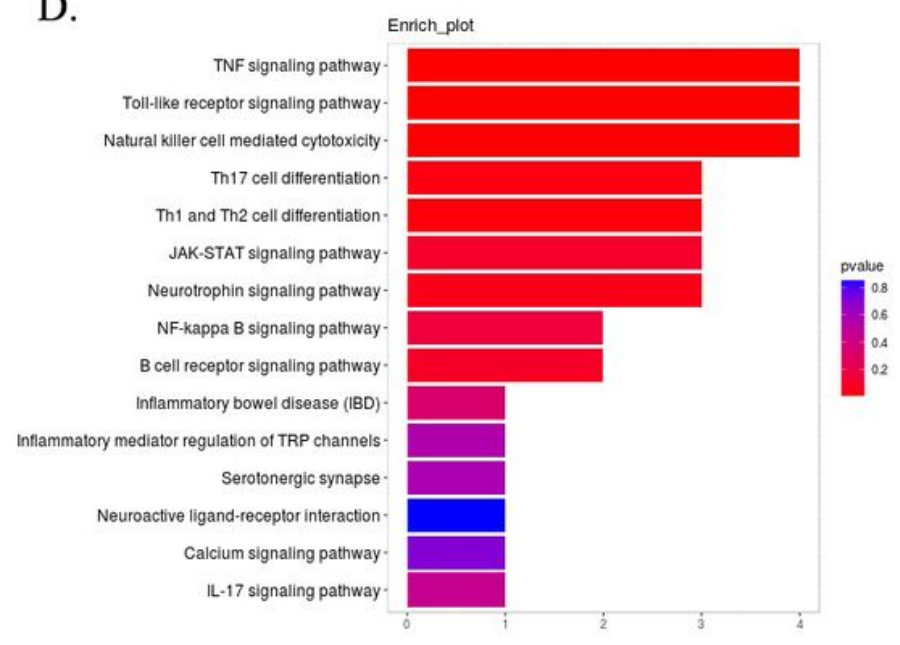

\section{Figure 5}

Bioinformatics analysis of GO and KEGG pathway. A and B: Prominently decreased GO responses (A) and KEGG pathways (B) on the sides of denervation (Right), compared with the normal side (Left) in Group 1. $C$ and D: Prominently decreased responses (C) and pathways (D) after denervation surgery in Group 2, respectively. 
A.

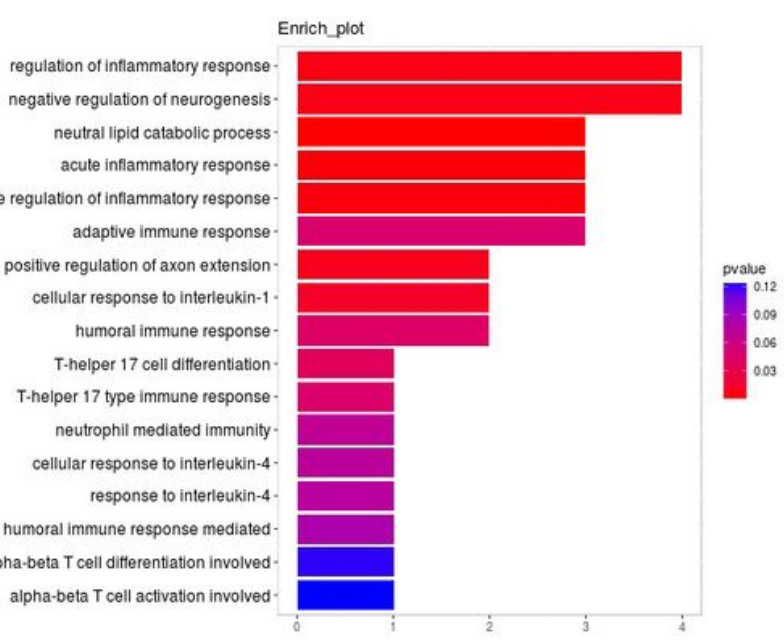

C.

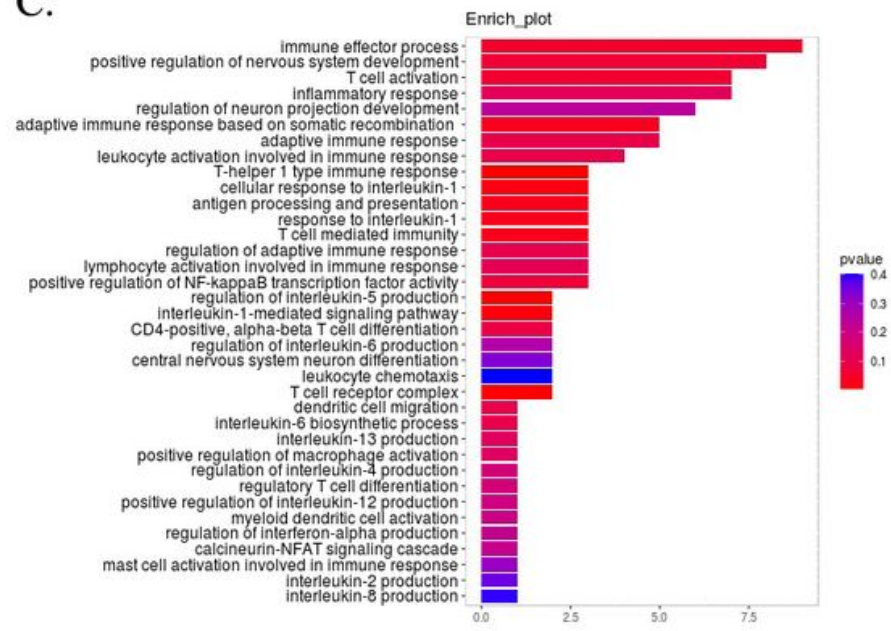

B.

Enrich_plot

Complement and coagulation cascades

Antigen processing and presentation

Th17 cell differentiation

IL-17 signaling pathway

Inflammatory bowel disease (IBD)

Neuroactive ligand-receptor interaction
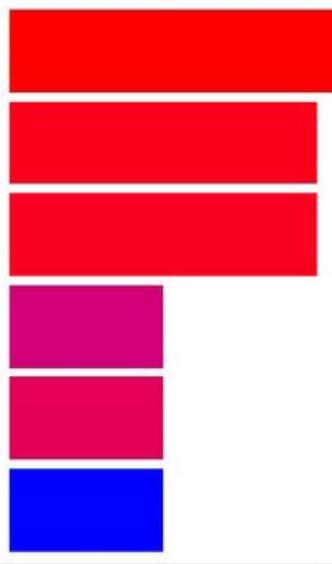

D.

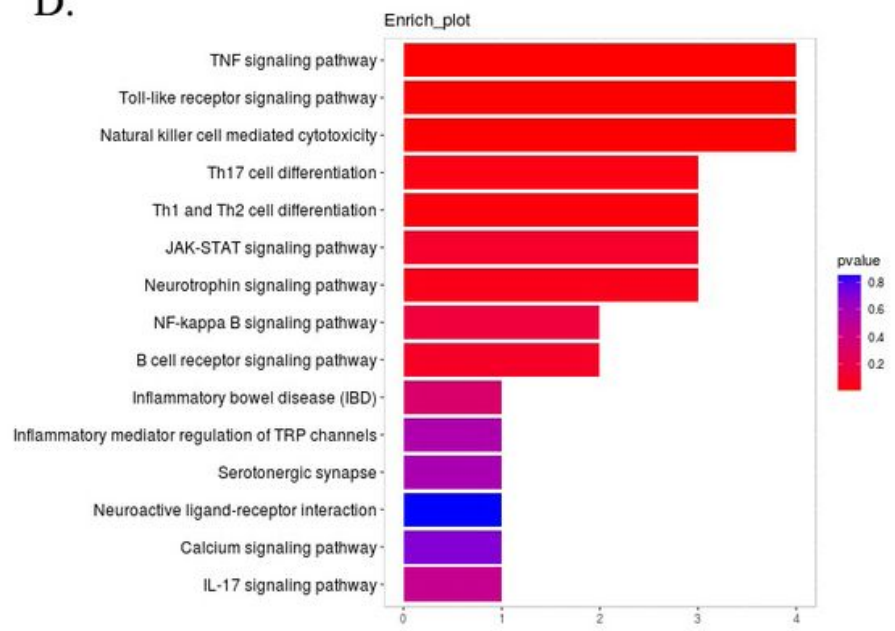

\section{Figure 5}

Bioinformatics analysis of GO and KEGG pathway. A and B: Prominently decreased GO responses (A) and KEGG pathways (B) on the sides of denervation (Right), compared with the normal side (Left) in Group 1. C and D: Prominently decreased responses (C) and pathways (D) after denervation surgery in Group 2, respectively. 
A.

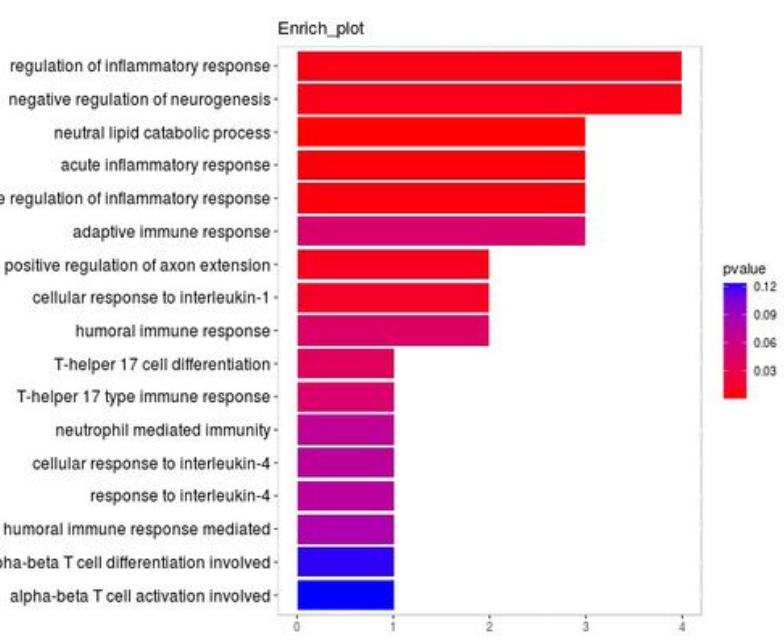

C.

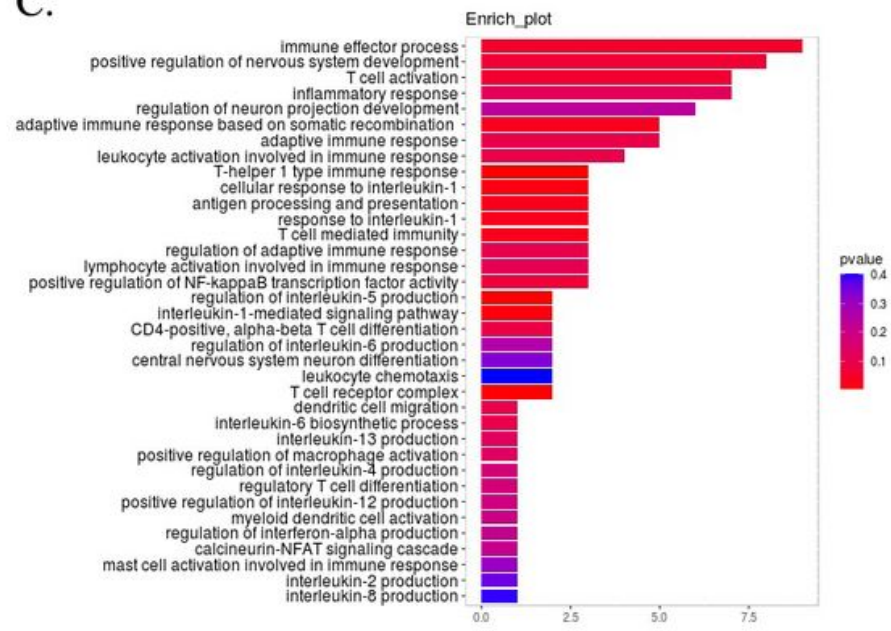

B.

Enrich_plot

Complement and coagulation cascades

Antigen processing and presentation

Th17 cell differentiation

IL-17 signaling pathway

Inflammatory bowel disease (IBD)

Neuroactive ligand-receptor interaction
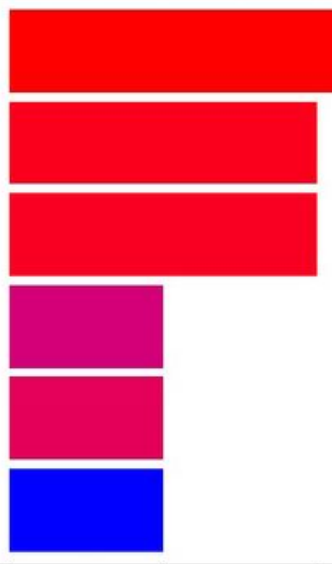

D.

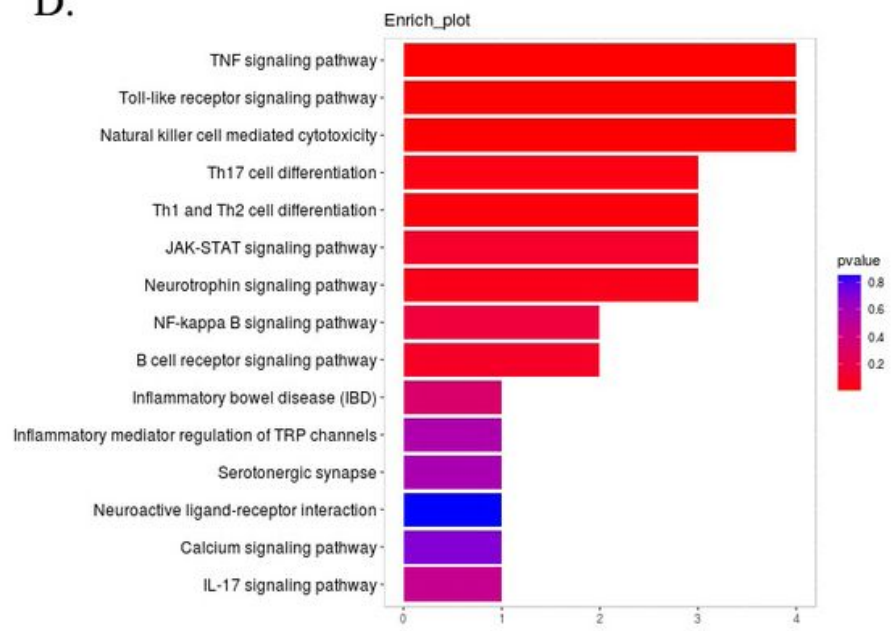

\section{Figure 5}

Bioinformatics analysis of GO and KEGG pathway. A and B: Prominently decreased GO responses (A) and KEGG pathways (B) on the sides of denervation (Right), compared with the normal side (Left) in Group 1. C and D: Prominently decreased responses (C) and pathways (D) after denervation surgery in Group 2, respectively. 
A.

regulation of inflammatory response

negative regulation of neurogenesis -

neutral lipid catabolic process -

acute inflammatory response -

negative regulation of inflammatory response adaptive immune response

positive regulation of axon extension cellular response to interleukin-1.

humoral immune response -

T-helper 17 cell ditterentiation.

T-helper 17 type immune response -

neutrophil mediated immunity.

cellular response to interleukin-4

response to interleukin-4.

antimicrobial humoral immune response mediated

alpha-beta T cell differentiation involved -

alpha-beta $T$ cell activation involved .

Enrich_plot
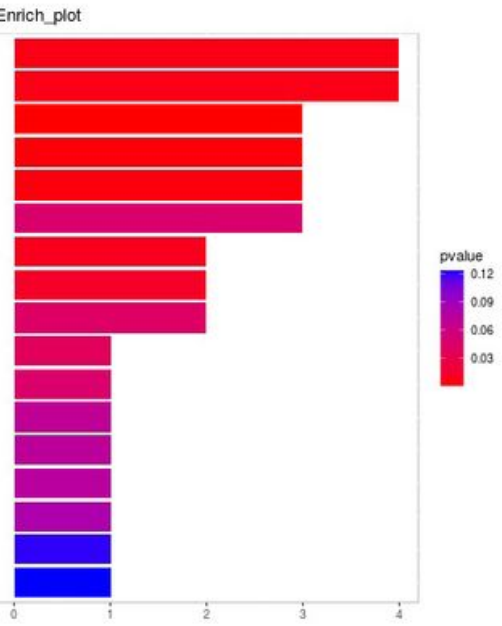

C.

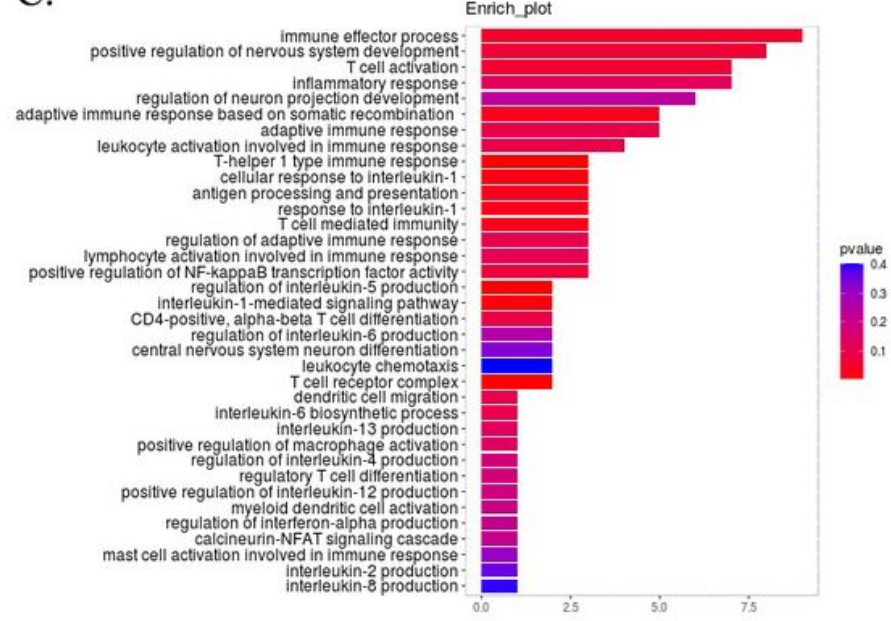

B.

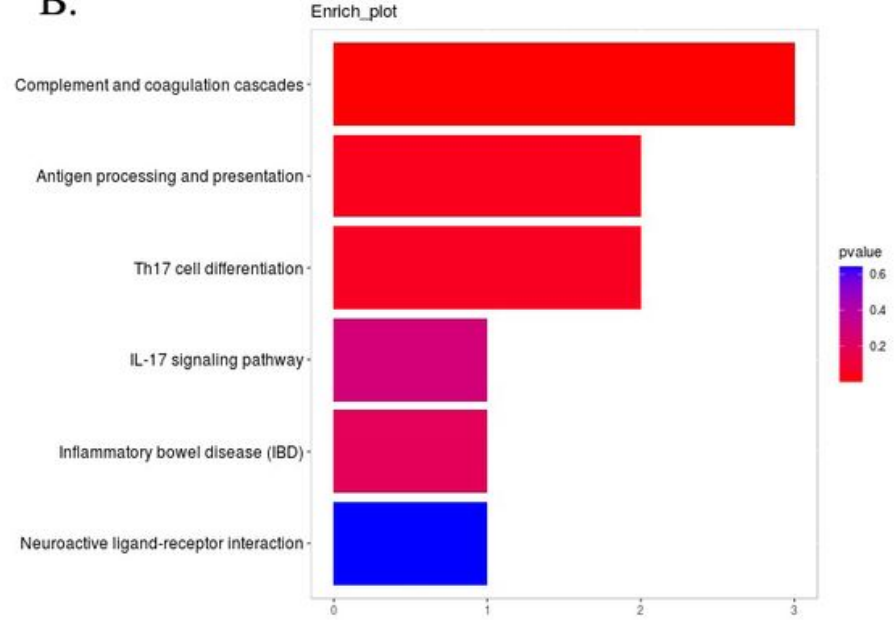

D.

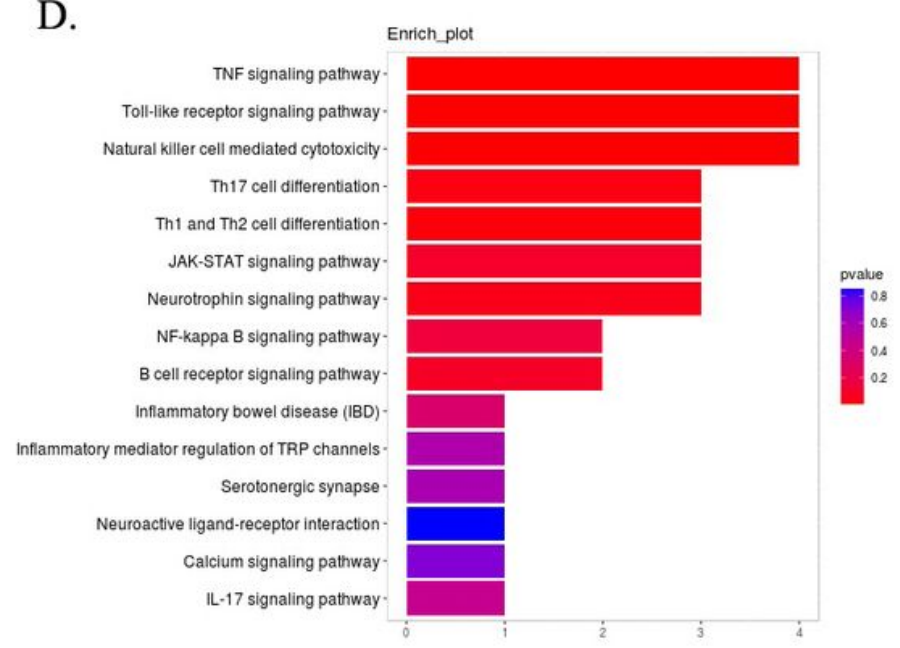

\section{Figure 5}

Bioinformatics analysis of GO and KEGG pathway. A and B: Prominently decreased GO responses $(A)$ and KEGG pathways (B) on the sides of denervation (Right), compared with the normal side (Left) in Group 1. $C$ and D: Prominently decreased responses (C) and pathways (D) after denervation surgery in Group 2, respectively.

\section{Supplementary Files}

This is a list of supplementary files associated with this preprint. Click to download.

- Supplementaryvideo.mp4

- Supplementaryvideo.mp4

- Supplementaryvideo.mp4

- Supplementaryvideo.mp4 
- Supplementarymaterial.docx

- Supplementarymaterial.docx

- Supplementarymaterial.docx

- Supplementarymaterial.docx 